The University of Maine

DigitalCommons@UMaine

Earth Science Faculty Scholarship

Earth Sciences

$10-27-1996$

\title{
Historical Biomass Burning: Late 19th Century Pioneer Agriculture Revolution in Northern Hemisphere Ice Core Data and its Atmospheric Interpretation
}

G. Holdsworth

K. Hiuchi

G. A. Zielinski

Paul Andrew Mayewski

University of Maine, paul.mayewski@maine.edu

M. Wahlen

See next page for additional authors

Follow this and additional works at: https://digitalcommons.library.umaine.edu/ers_facpub

Part of the Atmospheric Sciences Commons, Climate Commons, Geochemistry Commons, Glaciology Commons, and the Hydrology Commons

\section{Repository Citation}

Holdsworth, G.; Hiuchi, K.; Zielinski, G. A.; Mayewski, Paul Andrew; Wahlen, M.; Deck, B.; Chylek, P.; Johnson, B.; and Damiano, P., "Historical Biomass Burning: Late 19th Century Pioneer Agriculture Revolution in Northern Hemisphere Ice Core Data and its Atmospheric Interpretation" (1996). Earth Science Faculty Scholarship. 241.

https://digitalcommons.library.umaine.edu/ers_facpub/241

This Article is brought to you for free and open access by DigitalCommons@UMaine. It has been accepted for inclusion in Earth Science Faculty Scholarship by an authorized administrator of DigitalCommons@UMaine. For more information, please contact

um.library.technical.services@maine.edu. 
Authors

G. Holdsworth, K. Hiuchi, G. A. Zielinski, Paul Andrew Mayewski, M. Wahlen, B. Deck, P. Chylek, B. Johnson, and P. Damiano 


\title{
Historical biomass burning: Late 19th century pioneer agriculture revolution in northern hemisphere ice core data and its atmospheric interpretation
}

\author{
G. Holdsworth, ${ }^{1,2}$ K. Higuchi, ${ }^{3}$ G.A. Zielinski, ${ }^{2}$ P.A. Mayewski, ${ }^{2}$ M. Wahlen,${ }^{4}$ \\ B. Deck, ${ }^{4}$ P. Chylek, ${ }^{5}$ B.Johnson,${ }^{5}$ and P. Damiano ${ }^{5}$
}

\begin{abstract}
Ice core data from Yukon and Greenland spanning from 1750 to 1950 indicate that between $\sim 1850$ and $\leq 1910$ a clear atmospheric signal exists of an episodic biomass burning event that is referred to as the Pioneer Agriculture Revolution. This is best seen in $\mathrm{NH}_{4}^{+}$ion and particulate concentrations but also in some limited black carbon concentration data, where for all three quantities maximum levels reach about 3 times the prerevolution background concentrations. Tree cellulose $\delta^{13} \mathrm{C}$ data and some early, controversial, French, air $\mathrm{CO}_{2}$ data, occurring within the same time interval, are interpreted as providing other independent evidence for the same, mainly North American, late 19th century biomass burning event. Some hitherto problematic northern hemisphere ice core derived $\mathrm{CO}_{2}$ concentration data may now be interpreted as containing a biomass burn signal, and these data are compared, especially as to the time of occurrence, with all the other results. A global carbon cycle model simulation of atmospheric $\mathrm{CO}_{2}$ mixing ratios using a maximum input of $3 \mathrm{Gt}(\mathrm{C}) / \mathrm{yr}$ at northern midlatitudes produces "anomalous" $\mathrm{CO}_{2}$ levels close to some of the ice core carbon dioxide values. However, other values in this data set do not reasonably represent fully mixed atmospheric values. This suggests that these values might be transients but still "tracers" for biomass burning. Nevertheless, it appears possible that interhemispheric $\mathrm{CO}_{2}$ gradients of similar magnitude to the present one could have existed briefly late last century.
\end{abstract}

\section{Introduction}

The term "Pioneer Agriculture Revolution" (PIAGREV) used throughout this paper was first formulated by Leavitt [1991], who modified the original terminology of Wilson [1978]. Here its use is based on evidence for sustained, anthropogenically triggered biomass burning and related emissions that attained maximum intensity during the latter half of the 19th century. The main

\footnotetext{
${ }^{1}$ Arctic Institute of North America, University of Calgary, Alberta, and National Hydrology Research Centre, Saskatoon, Saskatchewan, Canada.

${ }^{2}$ Glacier Research Group, Institute for the Study of Earth, Oceans and Space, University of New Hampshire, Durham.

${ }^{3}$ Atmospheric Environment Service, Department of the Environment, Downsview, Ontario, Canada.

${ }^{4}$ Scripps Institution of Oceanography, University of Califomia, La Jolla.

${ }^{5}$ Atmospheric Science Program, Dalhousie University, Halifax, Nova Scotia, Canada.

Copyright 1996 by the American Geophysical Union

Paper number 96JD01158.

0148-0227/96/96JD-01158\$0900
}

stage of the event was referred to by Wilson [1978] as the "Pioneer Agriculture Explosion," a term which describes the rapid rise of biomass clearing and burning associated with agrarian activities that occurred, according to the tree core data, from about 1860 to 1890 . Wilson [1978] deconvoluted $\delta^{13} \mathrm{C}$ data from a single but free standing Californian Bristlecone pine core to compute the change in atmospheric $\mathrm{CO}_{2}$ concentration that the data implied. He estimated that the preindustrial revolution $\mathrm{CO}_{2}$ levels were close to 270 parts per million by volume (ppmv) and that over three decades it climbed to about 300 ppmv.

The biosphere-atmosphere process model that Wilson used is now considered to be oversimplified. Whereas Wilson assumed that the apparent magnitude of the event that he identified in one tree core was global in extent, our data are more indicative of the probably dominant North American component. This is also evidently the case for Wilson's data. It is now known that preindustrial $\mathrm{CO}_{2}$ levels were closer to averaging about 280 ppmv [Friedli et al., 1986; Wahlen et al., 1991] and that Wilson's "explosion step" in carbon dioxide was neither everywhere as large as he calculated nor as sudden, nor in one single step. Furthermore, many tree cores examined subsequently simply do not show any significant perturbation in $\delta^{13} \mathrm{C}$ during the PIAGREV. Such a result is due, evidently, to the complexities in the 
processes whereby the different isotopes of carbon are sequestered into tree cellulose, as well as to the length of the growing season and the position of the tree with respect to the major smoke plumes. Here it should be noted that the main burning season during the PIAGREV must have been several months in duration; in comparison, the growing season for many of the trees sampled by dendroclimatologists can be as short as 6 weeks (as in the case of the Bristlecone pine). The tree core data as a whole represents a curious enigma in terms of defining the PIAGREV, yet it still forms an important part of our evidence. Nevertheless, there is overwhelming glaciochemical and historical evidence that the PIAGREV was a real event. The fact that the signature of the PIAGREV has been left in several essentially independent domains strengthens the overall interpretation of the event.

The main activities associated with the agriculture revolution were the cutting of forest stands and the clearing of vast tracts of land for agricultural purposes and the burning of wood, both as a means of removal and for domestic heating. Contemporaneous with these activities were the tilling and repeated ploughing of the soil. This activity introduced mineral and organic soil particles into the atmosphere. It has been estimated [Wong, 1978] that for the contiguous United States, $25 \%$ of the forest area was cleared during the 19th century. In addition to natural forest fires, many large "controlled" and uncontrolled fires occurred in midlatitude North America, particularly during the latter quarter of last century. Whereas wooden buildings initially sequestered carbon, large property fires, sometimes involving whole towns (as in the case of Seattle, Spokane, Ellensburg, and Vancouver in 1889 [Gould, 1938]) suddenly injected large amounts of particulate matter, carbon dioxide, and other gases into the atmosphere. Enhanced levels of black carbon would also have been introduced into the atmosphere during this time. The opening up of vast tracts of interior North America with the building of the railway system during the latter half of the last century must have played an important role in the PIAGREV.

Here, using ice core data, we are able to trace, in more detail than before, the course of the PIAGREV in the northern hemisphere. Principal evidence for the PIAGREV comes from ice core sites in central and southern Greenland and on Mount Logan (Yukon, Canada). After reviewing the nature of the ice core sites and their positions with respect to emission sources, previously published and new data are presented to show that there were sustained biospheric emissions during the period from about 1850 to 1900 . New detail for the course of the PIAGREV comes from ice core chemical data, from existing but selected tree ring data, and from direct air measurements made late last century. These latter measurements were discussed by several authors in some detail between 1982 and 1985 in the journal $\mathrm{Cli}$ matic Change. Stanhill [1982] stated that one particular series of the French data was "compatible with the hypothesis that a major and variable nonfossil fuel source of atmospheric $\mathrm{CO}_{2}$ was active during the last quarter of the nineteenth century." Even so, it was evident that these data were highly controversial. However, seen in the light of the present ice core data, some of the French direct-air $\mathrm{CO}_{2}$ concentration data now take on a supportive role in defining part of the PIAGREV.

Some previously unpublished "anomalous" ice core $\mathrm{CO}_{2}$ results from Mount Logan and some recently published data for Greenland [Wahlen et al., 1991] are now indirectly and qualitatively supported by the chemical ice core evidence presented here. Finally, to determine if the $\mathrm{CO}_{2}$ data are realistic, we used an estimated carbon input function (derived from published estimates and from new data presented here) in a global carbon cycle model. The complexity of carbon sink functions (involving the well-known "missing sink") make this exercise somewhat qualitative, but results are presented which show a small perturbation in atmospheric carbon dioxide in the high latitudes of the northern hemisphere during the PIAGREV. Whereas the global atmospheric carbon cycle model computes $\mathrm{CO}_{2}$ concentrations in a fully mixed atmosphere after each time step, we interpret some of the ice core $\mathrm{CO}_{2}$ concentration data as not being representative of a fully mixed atmosphere. This does not necessarily detract from the value of those data, which can still be used qualitatively as a "tracer" for the most intense phases of the PIAGREV.

Several sources of information suggest that the PIAGREV event consisted of two main episodes. Peaks in activity evidently occurred between about 1850 to 1860 and between about 1890 to 1900 , the second episode (or emission pulse) being the larger one. In the last decades of last century the major railways of North America were being established, and the second pulse of the PIAGREV may be directly and indirectly associated with that event.

The evidence presented here strongly suggests that the Antarctic ice core sites are not very "sensitive" to short-term transient events in the middle to high latitudes of the northern hemisphere, yet the Antarctic ice core gas data have usually been used to describe the state of the global atmosphere prior to about the middle of the 20th century. Most importantly, the northern hemisphere ice cores contain information on trace gases that is not immediately apparent in the high-latitude ice cores of the southern hemisphere. This is somewhat surprising considering that there were concurrent pioneer agricultural activities taking place in the southern hemisphere [Wilson, 1978] and that some exposed trees in coastal South America show a $\delta^{13} \mathrm{C}$ decrease at the time of the PIAGREV. The observation that other southern hemisphere trees do not show this underscores the important fact that tree $\delta^{13} \mathrm{C}$ data are often very difficult to interpret. This is apparent from the very rich literature on the subject. Recent developments in modeling forest fire plume transport on a hemispheric scale [e.g., Iacobellss et al., 1994] seem to provide a means of interpreting some of the large variability in the ice core and the tree ring data, and particularly between differences in the published tree $\delta^{13} \mathrm{C}$ data. 
The philosophy of this paper is based on an interdisciplinary approach to problem solving and on the principle that multiple pieces of independent evidence, which on their own would hardly be sufficient to support a thesis, accumulate a higher degree of probability when considered in combination. Thus a "cumulative probability" results that must be significantly greater than any one of the individual probabilities attached to each single piece of evidence. This concept is given a formal but not a rigorous basis at the end of the section synthesizing the evidence for the PIAGREV.

\section{Ice Core Sites and Data Overview}

The names and locations of the principal ice core sites are as follows: "GISP2" $\left(72.2^{\circ} \mathrm{N} ; 37.8^{\circ} \mathrm{W} ; 3200 \mathrm{~m}\right.$ elevation above sea level (asl)) is in central Greenland, 20D $\left(64.99^{\circ} \mathrm{N} ; 44.44^{\circ} \mathrm{W} ; 2625 \mathrm{~m}\right.$ elevation asl) is in southern Greenland, and the Mount Logan site $\left(60.62^{\circ} \mathrm{N}\right.$; $140.52^{\circ} \mathrm{W}$; $5347 \mathrm{~m}$ elevation asl) is in the St. Elias Mountains, Yukon, Canada. Published data from the Crête (Greenland) ice core site (110 km south of GISP2; $3170 \mathrm{~m}$ elevation asl) is also used. GISP2 and Mount Logan are the coldest sites available in their respective regions, with mean annual temperatures of $-30 \pm 1^{\circ} \mathrm{C}$. The two sites, one in central Greenland [Wahlen et al., 1991] (site temperature $-31^{\circ} \mathrm{C} \pm 0.5^{\circ}$ ) and the other in the St. Elias Mountains [Holdsworth et al., 1992] $\left(-29^{\circ} \mathrm{C}\right.$ $\left.\pm 0.5^{\circ}\right)$, lie essentially in the melt-free "polar snow" zone [Benson, 1962]. This thermal regime is important for the preservation of chemical species in the snow. It is especially important when studying past $\mathrm{CO}_{2}$ concentrations in cores where the "ice" formed from dry snow. The formation of ice at the surface will sequester $\mathrm{CO}_{2}$ which will subsequently contaminate the core in the region at depth where the interstices between grains are sealing off a sample of the atmospheric air. Careful core sampling will reveal the local contamination, enabling the "correct" atmospheric sample to be obtained [Stauffer et al., 1985].

Carbon dioxide data for the GISP2 site are already published [Wahlen et al., 1991] but were not fully interpreted at that time. There, the formation of ice at the surface is rare, and strict sampling procedures were used which discriminated against surface-formed "ice" in the core. At the site on Mount Logan, transient meltwater ice lenses have not been seen in the recent snowpack. These would affect not only gas adsorption but also soluble ion concentrations at the surface. Ice lensing is unlikely to have occurred significantly during the last, generally colder, three centuries, which the core spans. However, hard (high density) riming [Alford and Keeler, 1970; Labelle, 1974; G. Holdsworth, unpublished data, 1986, 1988] occurs infrequently but is one possible cause for sporadic anomalies seen in $~ 9 \%$ of part of the Mount Logan $\mathrm{CO}_{2}$ concentration data obtained in 1984 [Claud, 1985]. These data will not be presented here because of the general difficulty in interpreting all the anomalies that seem to be present in those data. It has been suggested that acid-base reactions at grain boundaries may generate "excess" $\mathrm{CO}_{2}$ [Delmas, 1993], but we do not have convincing in situ ice core chemical evidence to support this model. If this chemical process has occurred in our samples, then, because of its position in the core, a necessary increase in carbonate dust influx would have been required about a century earlier than when the PIAGREV-era gas was trapped. Then, the $\mathrm{CO}_{2}$ anomalies (as well as the carbonate mineral dust) would be unrelated to the PIAGREV. There are, however, other possibilities for the anomalous $\mathrm{CO}_{2}$ concentrations in the ice core.

When only trace gas data with the lowest error bars are selected from the Mount Logan ice core data set, the "excess" $\mathrm{CO}_{2}$ anomalies (above the Antarctic $\mathrm{CO}_{2}$ reference curve) have a striking correspondence in time with the PIAGREV emission history to be described. This is also the case for the GISP2 data. Riming (solid condensate from a supercooled, supersaturated atmosphere) onto the surfaces of sastrugi (snow dunes), particularly on Mount Logan, may also have affected trace gas (and chemical species) enrichment factors, but we are not currently able to quantify this process.

Major chemical time series for the GISP2 core have been presented by Mayewski et al. [1993]. The diagnostic pulses of the PIAGREV may be seen in the $\mathrm{NH}_{4}^{+}$ series. Just after AD 1900, when $\mathrm{NH}_{4}^{+}$concentrations decline to pre-PIAGREV levels, both (non-seasalt) $\mathrm{SO}_{4}^{\overline{4}}$ and $\mathrm{NO}_{3}^{+}$begin climbing, indicating the switch from mainly biomass fuel burning to predominantly fossil fuel combustion.

Core from the southern Greenland site (20D) (mean annual temperature about $-20^{\circ} \mathrm{C}$ ) has provided interpretable time series of the soluble ions over the last two centuries [Mayewski et al., 1990; Dibb et al., unpublished data]. One of these time series $\left(\mathrm{NH}_{4}^{+}\right)$is used here, with the GISP2 data, as primary evidence for the biomass burning component of the PIAGREV. Trace $\mathrm{CH}_{4}$ and $\mathrm{N}_{2} \mathrm{O}$ data from this site and from Mount Logan and relevant to the PIAGREV have been presented elsewhere [Dibb et al., 1993]. We now present the primary data used in building up a self-consistent description of the PIAGREV.

We have reported the data as the original ionic (or other component) concentrations in the ice core meltwater, rather than converting to fluxes. Although, in principle, this step could be taken, since the timescales and annual increments are known very well, we have not done so because there are too many uncertainties associated with atmospheric and surface snow processes occurring at the ice core sites involved [Dibb et al., 1992]. The carbon input function used in the global carbon cycle model is a flux, but it was generated using (as a guide) published fluxes derived from tree core $\delta^{13} \mathrm{C}$ data together with form functions derived from the ice core data.

\section{Data and Results}

We first present data that are strongly associated with known agricultural activities which occurred (pri- 
marily in North America) during the latter half of the 19 th century. Several ions (including $\mathrm{NH}_{4}^{+}$) associated with biomass burn compounds have been identified in Greenland cores [Legrand et al., 1992; Whitlow et al., 1994].

\section{Ammonium Data}

Figure 1 shows the $\mathrm{NH}_{4}^{+}$ion concentrations in the GISP2 and 20D cores. Enhanced levels occur between $\sim 1850$ and $\sim 1920$, with a prominent minima occurring at $A D 1875 \pm 5$. These are the highest sustained levels reached in the complete 20D core as well as the GISP2 core from AD 1650 to present. At Mount Logan, there are spikes corresponding to the Greenland spikes [Whitlow et al., 1994], but they are of the same order of magnitude as other spikes in the core. It is possible that the Mount Logan core site is regularly recording a relatively high level of forest fire chemistry from naturally occurring wildfires in the Yukon and Alaska (and also probably Siberia) and that the $\mathrm{NH}_{3}\left(\mathrm{NH}_{4}^{+}\right)$signal from more southern (PIAGREV) sources would have attenuated to low levels after air associated with those emissions completed a circuit around the northern hemisphere (usual transit time of the order of $\sim 10$ days). The residence time of ammonia in the troposphere is probably of the order of a few days. On the other hand, the Greenland Ice Sheet is very well situated for recording direct anthropogenic emissions from central North America [Mayewski et al., 1990]. The transit time here is short and probably of the order of the residence time of gaseous ammonia in the lower troposphere.

\section{Black Carbon (Soot) Data}

It is reasonable to associate the presence of elemental carbon (and other carbonaceous materials) in ice cores with mainly combusted, or sometimes incompletely combusted, terrestrial biomass or fossil hydrocarbons. The method used for analyzing carbon in the ice cores is based on measuring the light transmittance through a particle-trapping quartz filter before and after combustion at $700^{\circ} \mathrm{C}$ [Chylek et al., 1992]. All carbonaceous material is thus converted to gaseous form and expelled. There is thus no discrimination made between graphitic carbon and partly, or even wholly, uncombusted substances (such as lignins) on the filter. Because the origins of all such atmospheric carbonaceous materials during the PIAGREV were probably closely related, the data presented are assumed to broadly represent that event in a qualitative, integrated way. Thus the reference to "graphitic carbon," black carbon (or soot) is used here in a rather loose sense. In Figure 2, we present the results of the carbon analyses carried out on all remaining but discontinuous samples of Mount Logan core at Dalhousie University. Three overlapping cores (A, C, and D) were used. Core D has been dated accurately [Holdsworth et al., 1992]. The other, shorter, cores are keyed to it by cross-correlation using isotopic and chemical time series. Core $A$ is 100 $m$ south of the site where the contiguous cores $C$ and D were taken on the NW Col of Mount Logan. We do not yet have high-resolution data for Greenland within the same time interval, but one should expect that carbon concentrations would show similar characteristics to the form shown in Figure 2, because this nonreac-

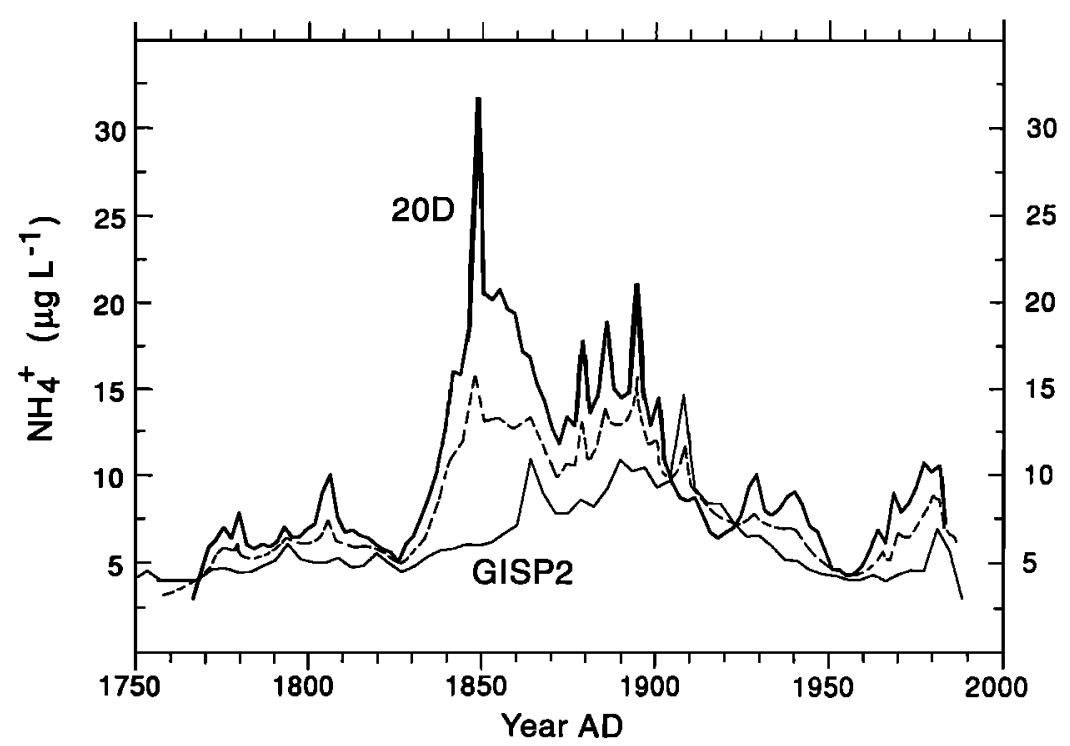

Figure 1. Plot of $\mathrm{NH}_{4}^{+}$ion concentrations for two Greenland ice cores: 20D in southern Greenland (thick curve based on filtered subannual data) and Greenland Ice Sheet Project 2 (GISP2) central summit (thin curve based on filtered biannual data). The dashed line is the mean value curve. Enhanced values from 1850 to 1910 are indicative of North American biomass burning during the Pioneer Agriculture Revolution. The existence of the two prominent peaks is assumed to be mainly related to biomass burning history and is used in estimating the shape of the source function in the carbon- cycle model (see Fig. 5). 


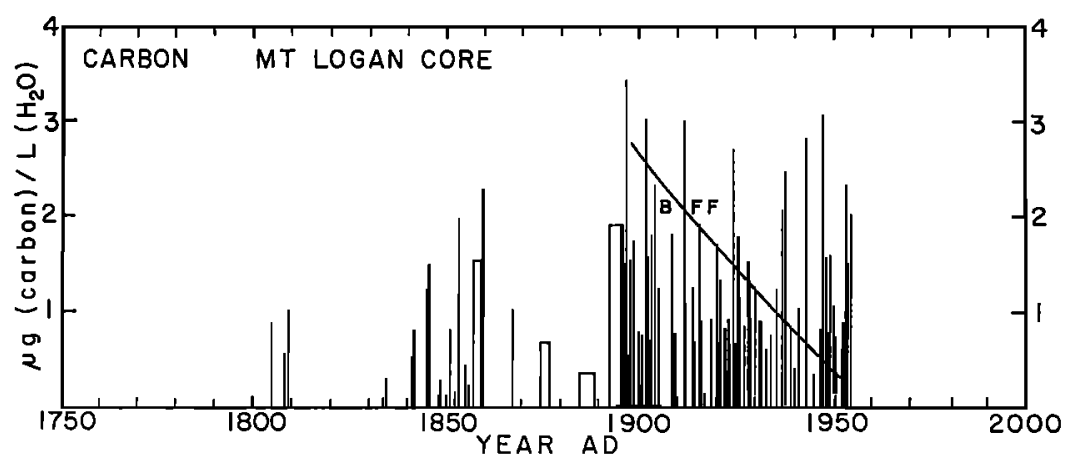

Figure 2. Black carbon concentration ( $\mu \mathrm{g} \mathrm{C} / \mathrm{L}$ meltwater) in the Mount Logan ice cores [Holdsworth et al., 1992]. Mean values are shown by blocks; otherwise, single-year values are shown by vertical line (subannual variations shown by adjacent short and long lines). Gaps in record are due to limited availability of remaining core.

tive tracer appears to be showing the same variations as the Greenland $\mathrm{NH}_{4}^{+}$data, which suggests a hemispheric "soot" signal of the PIAGREV. In support of this, Junge [1963] found that insoluble aerosols have a fairly uniform concentration for a few kilometers above about $5 \mathrm{~km}$ altitude. The Mount Logan ice core site is located in this part of the troposphere. It thus appears that temporary mixing occurs at these altitudes and that residence times of the solid particles (such as soot) will be much longer than that of gaseous (fire) derivatives, such as ammonia.

Referring to Figure 2, it must be realized, however, that after about 1910, carbon sources from increasing fossil fuel combustion started to become important and that these early 20 th century sources were not subjected to emission controls. Thus the maintenance of high levels of nonforest fire carbon after about 1910 is to be expected. In this respect, the Mount Logan site would seem to be a good receptor for soot transported long distances in the northern hemisphere. The amounts of carbon contributed from local fires is not known. Also, because the chemistries and transports of ammonia and soot are quite different, it is not surprising that the $\mathrm{C}$ and $\mathrm{NH}_{4}^{+}$time series [Whitlow et al., 1994] from the Mount Logan core do not look very similar. Because the Greenland $\mathrm{NH}_{4}^{+}$signal is of similar form to several other time series of PIAGREV indicators at different locations (as described in this paper), it is thought that during the PIAGREV the North American contribution to atmospheric loading probably tended to dominate.

\section{Microparticle Data}

Insoluble microparticle concentrations for the GISP2 core are presented in Figure 3. The particles are assumed to be mineral matter and soil as well as burned or unburned biomass material. These data further support the influence of the PIAGREV on the remote atmosphere in Greenland. Peaks in microparticle concentrations over the last 250 years occur around 1850 to 1870,1885 to almost 1900 , and again between 1910 and 1920, time periods that closely coincide with maximum biomass burning indicated by increases in ammonium levels (Fig. 1). The increases in particle mass occurring during these same general time periods (Fig. 3 ) reflect an increase in the abundance of larger particles. Higher particle concentrations imply greater at-

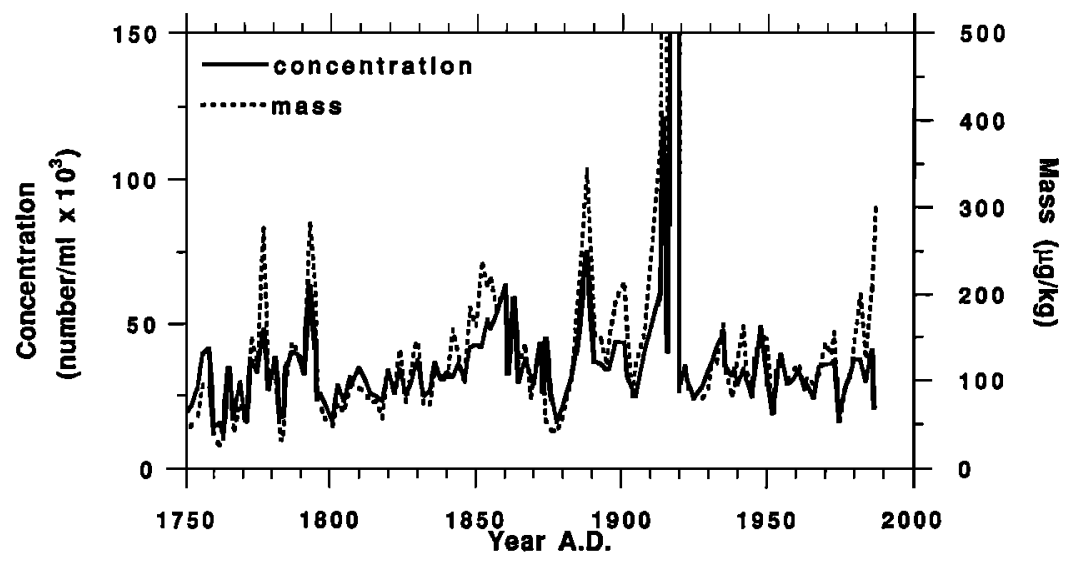

Figure 3. Plot of insoluble microparticle concentrations and mass in the 0.65 - to $13-\mu \mathrm{m}$ size range from biyearly samples in the GISP2 ice core. Particle numbers were determined with an Elzone ${ }^{\mathrm{TM}}$ particle counter. Mass values were calculated assuming a particle density of 2.65 $\mathrm{g} / \mathrm{cm}^{3}$. 
mospheric turbidity during PIAGREV, probably from the known clear-cutting, biomass burning, and tilling of top soil at that time. Such actions would increase the amount of material available for transport by wind to Greenland. We next look at other sources of data that support the existence of the PIAGREV.

\section{Ice Core Carbon Dioxide Data}

Ice cores from glacier sites where the mean annual temperature is less than about $-25^{\circ} \mathrm{C}$ are generally thought to trap atmospheric trace gases at about the same mixing ratio as they had in the free atmosphere [Raynaud and Barnola, 1985]. The one proviso is that there should be no melt-ice formation at the surface or near surface; otherwise, excess $\mathrm{CO}_{2}$ will be sequestered into the snowpack. However, suitable sampling can usually be made to avoid such ice layers [Stauffer et al., 1985]. Another process that could sequester $\mathrm{CO}_{2}$ in the surface snowpack is hard riming (derived from supercooled water droplets occurring in clouds at low temperatures). This process may occur more readily at high-altitude sites such as on Mount Logan.

In Table 1 we present the results of the most reliable, previously unpublished, analyses of the Mount Logan ice core made using the "French technique" [Raynaud and Barnola, 1985]. For the new Mount Logan data the error on the estimated age [Schwander, 1989] of the bubble air is typically \pm 6 years. Because the combined ice core data set merges with the "instrumental" data set, a degree of confidence in the ice core timescales is implied. It should be noted that the Mount Logan carbon dioxide data presented here is based on analyses carried out in 1981 and 1988 at the Laboratoire de Glaciologie et Geophysique de L'Environnement, Grenoble. It is thus necessary to discuss these particular data in much more detail here than the Greenland data which have been published and documented elsewhere.

Note on the Time Offset Between the Age of the Air in the Bubbles and the Age of the Ice Surrounding Them

The gas/ice age offset for the Mount Logan core was taken by $D i b b$ et al. [1993] as $103 \pm 5.5$ years. Here we take the offset as 100 years as this produces the best match with the Greenland ice sheet $\mathrm{CO}_{2}$ data, to be presented. The gas/ice age offset of the GISP2 data [Wahlen et al., 1991] is $\sim 220$ years. The age error bars on the Greenland data [Staffelbach et al., 1991; Wahlen et al., 1991] must be of the order of a decade in order for the data to connect with the atmospheric data set [Keeling et al., 1989]. There may still be an unresolved constant offset error ( $\leq 10 \mathrm{yrs}$ ) between the different ice core data sets that are presented later.

Close-off at the firn-ice transition even in a summer/fall season (when smoke levels tend to be greatest) is quite rapid (compared with many high polar glacier sites), as the vertical flow rate of the ice at $65-\mathrm{m}$ depth is $\sim 0.25 \mathrm{~m} / \mathrm{yr}$. This may be compared with the ice core sampling interval. Gas subsampling was made at 3 - to $4-\mathrm{cm}$ intervals (Table 1 footnote), so that one in situ ice subsample would have had its air bubbles sealed off in $\sim 1.7$ months, which is well within the duration of a fire season. Because the site is situated on a saddle (col), where winds may reach jet stream speeds of $160 \mathrm{~km} / \mathrm{hr}$, the possibility for (summer) seasonal trace gas "contamination" in some air bubbles is evident. In contrast, the winter air would be more mixed. At this latitude the current seasonal $\mathrm{CO}_{2}$ variation is about 15 ppmv [Conway et al., 1988; Tanaka et al., 1988; Keeling et al., 1989]. Transient peaks in air trace gas concentrations would tend to be damped by diffusion processes in the firn, but we know of no reliable model (that applies to the Mount Logan NW Col site) to account for this.

The data presented in Table 1 is compatible with the Greenland ice core data. Significantly, the combined ice core $\mathrm{CO}_{2}$ data show temporal features that associate it with the PIAGREV. This important point will be demonstrated in a later section of the paper. Thus any attempted explanation of the high $\mathrm{CO}_{2}$ values based solely on in situ ice core chemical reactions [Delmas, 1993] would have to provide a reason why these reactions are concentrated in just those places. Because the chemical data available for the Mount Logan core do not seem to favor the process proposed by Delmas [1993], we do not attribute the anomalous $\mathrm{CO}_{2}$ values to in situ postdepositional processes. This would specifically require excess acid and/or excess carbonate

Table 1. Mean Concentrations of $\mathrm{CO}_{2}$ in Mount Logan "D" Ice Core

\begin{tabular}{ccc}
\hline Depth Interval, cm & Gas Age (AD) ${ }^{a}$ & {$\left[\mathrm{CO}_{2}\right]^{b}$ ppmv } \\
\hline $9993-10053$ & $1805 \pm 7$ & $275 \pm 8$ \\
$9920-9952$ & $1819 \pm 6$ & $285 \pm 7 ; 286 \pm 5$ \\
$9590-9688$ & $1839 \pm 6$ & $286 \pm 8$ \\
$9339-9366$ & $1860 \pm 6$ & $301 \pm 6^{c}$ \\
$8663-8696$ & $1897 \pm 5$ & $308 \pm 6 ; 309 \pm 7$ \\
\hline
\end{tabular}

${ }^{a}$ Gas/ice age offset used here is 100 years. The absolute age error bars for the Mount Logan data may be larger than those calculated.

${ }^{b}$ Mean of subsamples cut from $\frac{1}{2}$ core; subsample size: 3 to $4 \mathrm{~cm}$ vertical cuts.

'Oñe anomalous value removed. Analyses by J.-M. Barnola. Some 1984 data [Claud, 1985] (seven points) is excluded because of high error bars ( $>8$ ppmv) and the existence of several large spikes of unknown origin. However, some of those data are consistent with the data given above. Interpretion of those data should be investigated. 
salts occurring in close proximity. (Although there is a higher than average $\mathrm{Ca}^{++}$concentration from about 1760 to 1780 , the acid concentrations are lower than average. Ice in this interval is contiguous with bubble air a century younger in age. In addition, the middle of this last interval (where the gas age is 1870 ) was not marked by particularly high values of the principal PIAGREV chemical "tracers," as our collected data tend to show). Furthermore, there is no quantitative support for in situ chemical reactions for the $\mathrm{CO}_{2}$ data of Wahlen et al. [1991]. Concentrations of $\mathrm{Ca}^{++}$and $\mathrm{Mg}^{++}$in the GISP2 core for the last millennium do not positively correlate with high values of $\mathrm{CO}_{2}$; in fact, almost the reverse (negative) relationship is observed.

\section{Presentation and Discussion of Supporting Data}

\section{Tree Core Data}

Because there are certain similarities among Figures 1,2 , and 3 (within the context of the PIAGREV), we have searched for and compiled data (from various published sources) which might also act as proxy for biomass burning activity. In Figure 4 , we show a selection of time series of $\delta^{13} \mathrm{C}$ gradients $\left(d \delta_{i} / d t\right.$, where $\delta_{i}$ are specific tree $\delta^{13} \mathrm{C}$ data and $t$ is time). These series are derived from various $\delta^{13} \mathrm{C}$ data [Freyer, 1978; Wilson, 1978; Freyer and Belacy, 1983; Stuiver et al., 1984; Freyer, 1986] determined from isotopic analysis of northern hemisphere tree ring samples. They have been plotted over the same time interval. To avoid an overconcentration of lines in Figure 4, we have omitted similar data that are also available from other references [e.g., Tans and Mook, 1980; Stuiver, 1986; Stuiver and Braziunas, 1987]. The combined series typically show a prominent reversal of gradient beginning somewhat before 1850. This increase in negative gradient corresponds to a decrease in $\delta^{13} \mathrm{C}$. Such a $\delta^{13} \mathrm{C}$ step, or ramp, occurring soon after $\sim 1850$, may be found in many (free standing) tree core records and has been interpreted [Freyer, 1978; Wilson, 1978; Peng et al., 1983; Stuiver, 1986] to signal a rapid increase in atmospheric $\mathrm{CO}_{2}$. However, there are other environmental influences such as climatic factors [Peng et al., 1983; Leavitt, 1993] or biomass-driven isotope fractionation chemistry [Francey and Farquhar, 1982] that affect $\delta^{13} \mathrm{C}$ in wood, and some northern hemisphere trees studied [Leavitt, 1993] do not appear to carry a clear $(\sim 1850+)$ signal near the start of the PIAGREV.

Another possibility for explaining part of the overall large variability in northern hemisphere tree core $\delta^{13} \mathrm{C}$ values during the PIAGREV may be from different degrees of exposure of sampled tree stands to $\mathrm{CO}_{2}$ plumes emanating from forest fires or other centers of massive $\mathrm{CO}_{2}$ generation. This may be deduced from the plume transport modeling results of Iacobellis et al. [1994], where $\mathrm{CO}_{2}$ concentrations of several ppmv above background may occur over large, continental-scale areas on a timescale of weeks.

Also, the $\delta^{13} \mathrm{C}$ PIAGREV signal was not identified in Tasmanian wood sampled more than a decade ago [Francey, 1981]. However, these data might more nearly

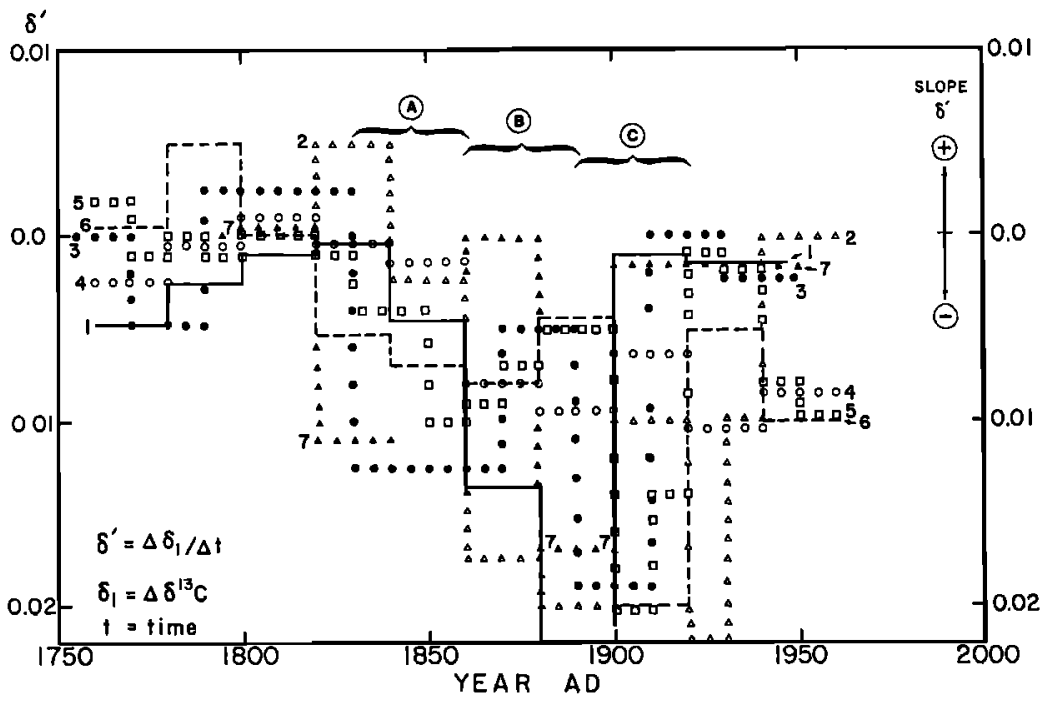

Figure 4. Processed $\delta^{13} \mathrm{C}$ data from various sources. Tree cellulose: curve 1 (solid line, 17601940), Wilson [1978]; curve 2 (open triangle), Freyer [1978]; curve 3 (solid circle), Freyer and Belacy [1983]; curve 4 (open circle), Stuiver et al. [1984]; curves 5 and 6 (open square, dashed), Freyer [1986]. Ice core air bubbles: curve 7 (solid triangle), Friedli et al. [1986]. Symbols (points) trace histograms of 20-year averaged time derivatives of deviations $\left(\delta_{i}\right)$ of the ${ }^{13} \mathrm{C}$ values from a designated mean [Freyer, 1986; Stuiver, 1986]. In some cases, a histogram "block" is missing because of large scatter of data in a 20-year interval. Spans A, B, and C define the three main stages of the Pioneer Agriculture Revolution (PIAGREV): A, explosion; B, postexplosion minimum; C, final maximum (see Fig. 5). 
reflect complex multivariate atmospheric and local tree chemistry variations [Francey and Farquhar, 1982] as they are not similar to other coastal southern hemisphere tree core $\delta^{13} \mathrm{C}$ data [Stuiver et al., 1984] from specially selected trees or to Antarctic ice core data [Friedli et al., 1986], which clearly show the decline in $\delta^{13} \mathrm{C}$ (consistent with an increase in the biospheric component of $\mathrm{CO}_{2}$ ) around 1850 . The error on the dating of the ice core air is given as \pm 11 years, and there was no stated correction made for possible gravitational and extraction isotopic fractionation effects. However, these are the only such data available at this time. Despite these limitations of the data, this situation should not significantly affect gross relative changes in the $\delta^{13} \mathrm{C}$ data and hence the time gradients which are shown (data set 7 ), together with the tree cellulose $\delta^{13} \mathrm{C}$ data, in Figure 4.

Considerable doubt still exists regarding the suitability of many tree $\delta^{13} \mathrm{C}$ series as reliable atmospheric indicators [Francey, 1981; Leavitt, 1993; Peng et al., 1983] emphasizing the fact that proper tree selection (as with ice core site selection) is very important [Stuiver et al., 1984]. Thus in the light of these considerations we acknowledge that the $(\sim 1850)$ tree $\delta^{13} \mathrm{C}$ anomaly could correspond, in part, to a change in the isotopic composition of atmospheric $\mathrm{CO}_{2}$ as a result of biomass burning or to a change in some climate variables (temperature, moisture content) or to changes in forest regime. This anomaly is hardly affected by absolute errors in $\delta^{13} \mathrm{C}$ determinations, which are suggested by a recent interlaboratory calibration exercise (C. S. Wong and M. Stuiver, personal communications, 1993). Regional differences in atmospheric variables as well as possible differences in reliability of data have made it difficult to identify a consistent $(1850+)$ signal in either hemisphere, but the majority of available time series contain it, particularly in the northern hemisphere, as one would expect [e.g., Freyer, 1978; Wilson, 1978; Freyer, 1979; Freyer and Belacy, 1983; Stuiver et al., 1984; Peng and Freyer, 1986; Stuiver and Braziunas, 1987].

Some of the inconsistencies among different tree core data sets may be due to the particular geometries of smoke (and gas) plume trajectories that evolve from the fire source. This is suggested by the $\mathrm{CO}_{2}$ transport modeling by Iacobellis et al. [1994]. Some trees have a very short wood-forming interval. For Bristlecone pine it is only about 6 weeks [Wilson, 1978]. The trees that were situated in a preferred plume path would show more depressed values of $\delta^{13} \mathrm{C}$ than trees well outside the plume path. Furthermore, in cases of extreme contamination by fire emissions, after cessation of those emissions or changes in the burn patterns, the $\delta^{13} \mathrm{C}$ values in the wood should recover toward a value more nearly representative of the value that pertains to a more fully mixed atmosphere. Some time series seem to show post-PIAGREV features that might be attributed to this effect [e.g., Freyer, 1986; Leavitt and Long, 1992], although climatic effects in this time interval may be just as important in affecting the tree $\delta^{13} \mathrm{C}$ values.

\section{Direct Air $\mathrm{CO}_{2}$ Data}

A number of different measurements of air $\mathrm{CO}_{2}$ content were made in the late 19th century. It is not possible here to present the complete data sets and discuss them. From and Keeling [1986] have discussed and apparently validated one particular data set obtained from coastal France by J. Reiset in 1872-1880. The remainder have been under considerable suspicion. One of those data sets (from the Montsouris Observatory) was considered reliable by Stanhill [1982], who further defended their integrity [Stanhill, 1983, 1984] against multiple criticisms [Waterman, 1983; Wigley, 1983; Siegenthaler, 1984]. The Montsouris data (to be presented later) show a prominent pulse in $\mathrm{CO}_{2}$ centered on about AD 1900. Whatever is the correct judgement on these data, we note that the relative variations within this data set are qualitatively consistent with some of the ice core data and the tree core data. The absolute values, however, do not appear to be those of a fully mixed atmosphere. (This condition also applies to the ice core and the tree ring data).

\section{Synthesis of Evidence for Deforestation, Biomass Burning, and Soil Cultivation and the Probability that Independent Data Sets Indicate the Same Event}

In summary, there are six lines of evidence suggesting intensified deforestation, cultivation, and biomass burning, particularly in North America, during the late 19 th and early 20 th centuries. These are (1) ice core $\mathrm{NH}_{4}^{+}$data, (2) ice core carbon data, (3) ice core microparticle concentrations, (4) ice core $\mathrm{CO}_{2}$ data (two independent sets), (5) tree cellulose $\delta^{13} \mathrm{C}$ data (multiple sets), and (6) direct air $\mathrm{CO}_{2}$ data. The peak biomass burning activity seems to have occurred within the interval AD 1889-1910 (see also Wong [1978] and Peng et al. [1983]). Although not entirely independent of the above evidence, another form of support is provided by the atmospheric modeling results, which provide a verification of the $\mathrm{CO}_{2}$ data.

The main signal for biomass burning comes from the $\mathrm{NH}_{4}^{+}$ion concentration data for the Greenland sites. The precursor gas for ammonium compounds in snow (e.g., $\left[\mathrm{NH}_{4}\right]_{2} \mathrm{SO}_{4}$ ) is ammonia gas, which is a constituent of forest fire smoke [Laursen et al., 1992; Levine et al., 1992]. $\mathrm{NH}_{3}$ may also be emitted from soils after forest burning. Legrand et al. [1992] have already pointed out the strong likelihood that ammonium spikes in pre-AD 1700, central Greenland snow originated from North American forest fires. Junge [1963] reported that atmospheric $\mathrm{NH}_{3}$ was measured in the second half of the 19 th century at various locations in western Europe, including the 2800-m-high site on Pic du Midi in France. The values were "rather high compared with more recent data" [Junge, 1963, p. 87]. This information may be used as supporting evidence for the PIAGREV. Re- 
cent forest fire plume transport simulations (S. F. Iacobellis, unpublished, 1994) indicate that North American emissions can impact both Greenland and Europe. Depending on the prevailing climatology, it is possible that anomalies of several ppmv above far-field mixed air existed on timescales of weeks. The levels of biomass burning may also have been high in western Europe late last century.

The carbon concentration data for Mount Logan was reported as soot, but we caution that it may include non-combusted carbonaceous matter as well. Before about 1900 the ice core carbonaceous material is assumed to be mainly from forest wood and other biomass destruction. The only data available for this study are from Mount Logan, Yukon. The data are sparse, but they show a variation with time which has similarities to the $\mathrm{NH}_{4}^{+}$data from Greenland up to the beginning of this century. This correlation (except for the most recent part of the data set) suggests that the Mount Logan site was a good receptor and indicator for mainly North American carbon emissions. With more complex emissions for the 20th century the condition of a "good indicator" may no longer apply. Additionally, the almost ubiquitous burning of fossil fuels with inefficient combustion before 1950 must be responsible for the high carbon levels during the first part of this century (Fig. 2).

The ice core microparticle concentrations for the GISP2 core show significantly higher levels and greater variance over the last half of the 19th century and the first two decades of the 20th century compared with the levels a century before and the seven decades after. The link with the PIAGREV in time suggests that the particulates were predominantly produced as a result of agricultural activities, such as tilling of newly exposed soils. The particulate inventory must also include various particles derived from burned or incompletely burned biomass material, such as is recorded in the data of Figure 2.

The northern hemisphere ice core $\mathrm{CO}_{2}$ data for the late 19th century have represented (with respect to the Antarctic data) an anomaly that was not easily interpreted until now. Seen in the context of the PIAGREV, these data appear to take on a particular significance, especially after global carbon cycle modeling (to be described) shows that elevated northern hemispheric carbon dioxide levels (over Antarctic values), in response to concentrated northern midlatitude biomass burning, could have occurred. In addition, as we have seen, some of the controversial French direct air $\mathrm{CO}_{2}$ data from late last century can be claimed to qualitatively support the ice core data.

Data from tree cores, usually in the form of time series of $\delta^{13} \mathrm{C}$, have been confusing and often contradictory. However, it is evident that in many free-standing trees there is a "signal" that corresponds in time to the PIAGREV. Where the ${ }^{13} \mathrm{C}$ step occurs, it is usually of the right order of magnitude to be explained predominantly by an increase in atmospheric $\mathrm{CO}_{2}$ [e.g., Stuiver et al., 1984]. Next, we look at the strength of the com- bined data sets that indicate the PIAGREV as being the common denominator.

\section{Probability Estimate for Combined Data}

Given that each data set described above has an individual probability of being related to a common event, the system of data sets provides a means of estimating the combined probability that the PIAGREV was a "fundamental" event. If, for simplicity, we initially take only three of the events and assign individual probabilities $\left[P\left(E_{i}\right) ;(i=1,2,3)\right]$ that they are all related to a single main event, $E$, we can estimate this combined probability $P(E)$ using the general addition law of probabilities [Chatfield, 1983]. The combined probability that the three "subevents" are related to the parent event $E$ is thus given by

$$
\begin{aligned}
& P(E)=P\left(\sum_{i=1}^{3} E_{i}\right)=P\left(E_{1}\right)+P\left(E_{2}\right)+P\left(E_{3}\right)- \\
& P\left(E_{1} E_{2}\right)-P\left(E_{2} E_{3}\right)-P\left(E_{1} E_{3}\right)+P\left(E_{1} E_{2} E_{3}\right) .
\end{aligned}
$$

Taking a relatively low probability of $P\left(E_{i}\right)=0.50$ for all three events, we calculate a combined probability of $P(E)=0.875$ that the three events are related to the parent event. Next, to accommodate the six events, we repeat this procedure for two combined "events" (each composed of three subevents) with a probability of 0.875 of being related to a common event (again $E$ ). The required equation is

$P^{\prime}(E)=P\left(E_{a}+E_{b}\right)=P\left(E_{a}\right)+P\left(E_{b}\right)-P\left(E_{a} E_{b}\right)$

where $E_{a}$ and $E_{b}$ are now each taken as equal to the previous $P(E)$.

We thus get a new probability, $P^{\prime}(E)=0.984$, which is close to the probability level acceptable in most statistical studies. Even using a less optimistic value of $P\left(E_{i}\right)=0.40$ ( $40 \%$ probability), the equations yield a value of $P^{\prime}(E)=0.954$, which is still within acceptable statistical limits. If we take a more confident value of $P\left(E_{i}\right)=0.60$ (and this would not be unrealistic for the combined ice core $\mathrm{CO}_{2}$ data, in which each data set would, of course, have a much lower individual probability), then we find that $P^{\prime}(E)=0.996$, which defines a very high statistical probability.

\section{Atmospheric Carbon Input Fluxes From Biomass Sources}

In 1860 , fossil fuel burning was taking place, but at a very low level compared to extant biomass burning [e.g., Keeling, 1973; Marland and Rotty, 1984; Marland, 1989; Marland et al., 1989]. Furthermore, carbon dioxide input to the atmosphere from this source was to remain very low until the start of the 20th century. Figure 5 shows various biomass carbon source functions (input into the atmosphere) which are possi- 


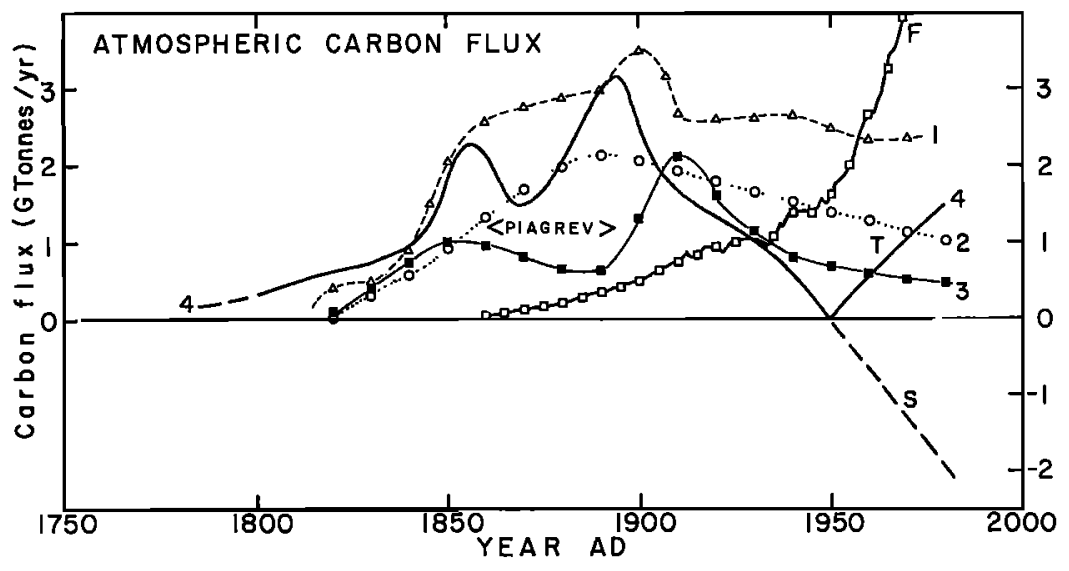

Figure 5. Estimated carbon input (Gt[C]/yr) to the atmosphere from biomass burning as derived from data shown in Figure 4 by different authors: curve 1, Freyer and Belacy [1983]; curves 2 and 3, Peng and Freyer [1986]. For clarity of presentation, not all published curves for this function are shown here. Curve 4 defines the estimated input function used in the global carbon cycle model to best producc an output showing the main features of the available $\mathrm{CO}_{2}$ data. This function is based on earlier, near-maximum estimates [Peng and Freyer, 1986; Stuiver, 1986] and modified according to information shown in Figures 1 and 2. Source is applied at northern hemisphere midlatitudes until 1950; thereafter it becomes a sink (dashed curve S) T, tropical source function. Curve F is the fossil fuel curve [Stuiver, 1986]. PIAGREV, Pioneer Agriculture Revolution.

ble in the light of several independent carbon budget studies [Higuchi, 1983a; Peng and Freyer, 1986; Stuiver, 1986; Siegenthaler and Oeschger, 1987; Tans et al., 1990], and which show the probable minimum and maximum limits of carbon input from natural and anthropogenically triggered sources. For a more complete coverage of the large differences in carbon input functions, see Peng and Freyer [1986]. The twin-peaked biomass source function that we constructed for our model study (to be described in a later section) was structured to reflect the variations in the $\mathrm{NH}_{4}^{+}$, carbon and particle concentrations (up to 11910 ) shown in Figures 1,2 and 3. The initial, trial function was set with a low amplitude at the level of the function derived by Peng and Freyer [1986]. The amplitude was successively increased until the model output produced $\mathrm{CO}_{2}$ levels that approximately fitted the combined $\mathrm{CO}_{2}$ data (to be presented in the next section) as closely as possible. It may be mentioned here that the $\delta^{13} \mathrm{C}$ data from the Antarctic ice core [Friedli et al., 1986] shows two possible drops, one about mid-19th century, the other (significantly larger) near 1900 (although these data are subject to absolute errors mentioned earlier, the relative errors should hardly be responsible for the most prominent variations seen in those data). Thus these observations are consistent with our twin-peaked atmospheric carbon input function. For this reason we have not attempted to interpret the variations in chemical species at the ice core sites in terms of major atmospheric circulation changes, for which reliable evidence throughout that time span is not presently available to us. We next examine, in detail, the available data for past levels of carbon dioxide in the atmosphere.

In contrast to the northern hemisphere $\mathrm{CO}_{2}$ data, the Antarctic $\mathrm{CO}_{2}$ data [Friedli et al., 1986; Enting, 1992] show a fairly smooth increase, but there are weak increases evident at $\sim 1850$ and 1900 that now have special significance because of the timing. An alternative explanation, that these variations merely represent measurement errors in the data, is hardly supported by the observation that the "excess" values occur at the two significant times of the PIAGREV. As we mentioned earlier, there is also the hint of two steps in the $\delta^{13} \mathrm{C}$ data of Freidli et al. [1994] at the same two times. These results imply that (1) some mixed PIAGREV $\mathrm{CO}_{2}$ may have reached high southern latitudes but that (2) sinks between middle northern latitudes and the Antarctic ice core sites largely absorbed the transient excess $\mathrm{CO}_{2}$. Next, we present the combined evidence for elevated $\mathrm{CO}_{2}$ levels (over Antarctic values) at specific locations in the northern hemisphere during the PIAGREV.

\section{Discussion of $\mathrm{CO}_{2}$ Data}

In Figure 6, we show ice core $\mathrm{CO}_{2}$ data (symbols with estimated error bars) obtained from the GISP2 site [Wahlen et al., 1991], the Crête ice core [Staffelbach et al., 1991], and the 1980 Mount Logan " $\mathrm{D}$ " core. The latter, previously unpublished data are taken from Table 1. It is thought that the time error between data sets is probably within about 10 years. Because of subsample averaging, the original atmospheric trace gas short-term (transient) variations are further reduced. However, the persistence of peaks in the data of Figure 6 seems to imply that significant levels of enrichment occurred over decadal timescales, which is consistent with the historical evidence as well as with the 19th century French air $\mathrm{CO}_{2}$ data that will be discussed later. Curve $a$ in 


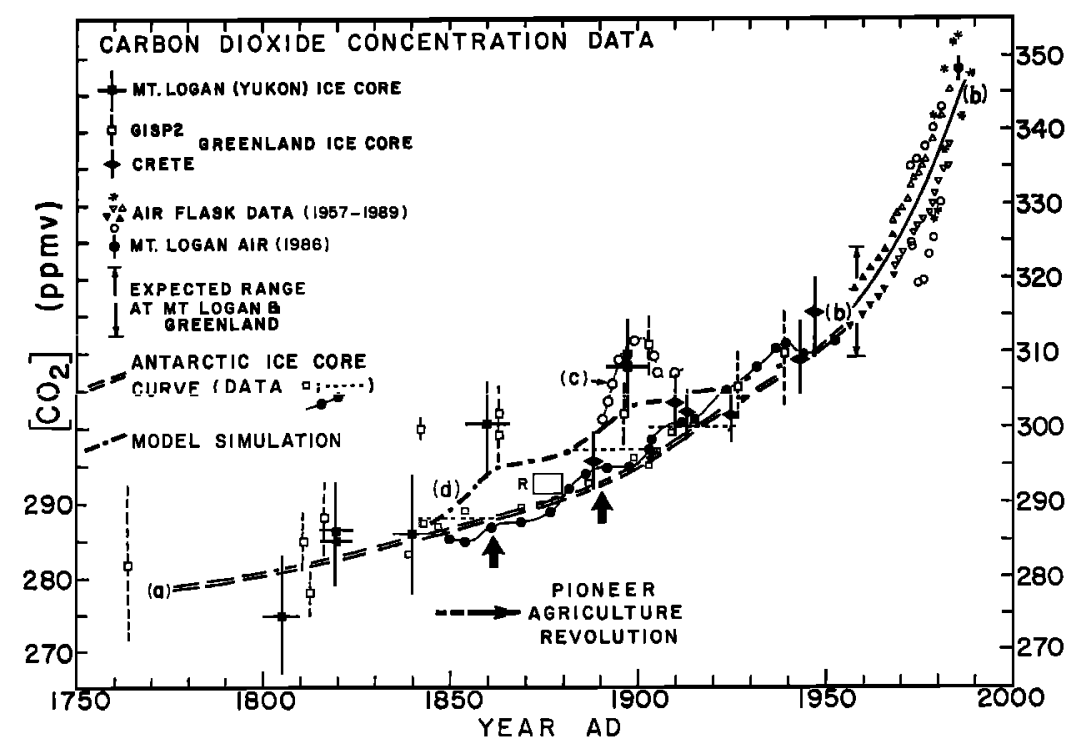

Figure 6. Two centuries of atmospheric carbon dioxide variations as suggested by various data sources and by model results. The double-dashed curve $a$ is a spline fit to the Antarctic (Siple Station) ice core data, here shifted 2 years to the right so that it lies (observationally) $\sim 1 \mathrm{ppmv}$ below the Mauna Loa data [Keeling et al., 1989] starting in 1958 (curve b) (range indicated by solid triangle and inverted solid triangle). Some individual Antarctic data points are shown either by small horizontal dashes (averages) or by small open squares [see Neftel et al., 1994]. (In addition, we have recently added the new data of Etheridge et al. [1996]. These data are shown by the solid circles connected by thin lines.) The two vertical arrows shown below curve $a$ indicate the location of possible perturbations that may be related to the PIAGREV. The symbols (open triangle, open inverted triangle, open circle, asterisk) define annual ranges at several coastal stations [Conway et al., 1988; Tanaka et al., 1988; Keeling et al., 1989] near $60^{\circ} \mathrm{N}$, adjusted to the altitude of Mount Logan. The capped arrows above and below the earliest Mauna Loa data define the estimated annual range at $60.5^{\circ} \mathrm{N}$ at the altitude of the Mount Logan site (similar for Greenland). $\mathrm{CO}_{2}$ data derived from northern hemisphere ice cores are shown as single points: (solid square) Mount Logan; (open square) GISP2, Greenland [Wahlen et al., 1991]; (solid diamond) Crête, Greenland [Staffelbach et al., 1991]. Error bars are estimated absolute values. Curve $c$ (joined open circles from 1890 to 1910) shows the measured variation of $\mathrm{CO}_{2}$ in the air at the Montsouris Observatory, near Paris, France [Stanhill, 1982]. The coastal French data of J. A. Reiset [From and Keeling, 1986] is shown in the block marked R. Curve $d$ : Model $\mathrm{CO}_{2}$ simulation for high-latitude northern hemisphere sites $\left(60^{\circ}-80^{\circ}\right)$ based on curve 4 and curve $\mathrm{F}$ input functions shown in Figure 5 and employing experimentally constructed sink functions to duplicate the Antarctic curve for high southern latitudes.

Figure 6 defines the Antarctic ice core data set [Friedli et al., 1986] spline fitted by Siegenthaler and Oeschger [1987] and here shifted 2 years to the right to produce an (observational) $\sim 1$ ppmv underfit with the Mauna Loa data [Keeling et al., 1989] (shown as curve $b$ ). Such a shift is still within the age error bar given for these data. Some of the original Antarctic ice core data values are shown at two significant times during the PIAGREV, marked by the vertical arrows below curve $a$.

Direct air measurements (data points) shown after 1958 , and defining seasonal ranges, are taken from Bischoff [1981], Conway et al. [1988], Tanaka et al. [1988], Keeling et al. [1989], and from air samples taken on Mount Logan in July 1986 (top solid circle). (Analyses of these samples are courtesy of C.S. Wong, Institute of Ocean Sciences, Sidney, B.C., Canada.) The expected annual range at Mount Logan $\left(60.5^{\circ} \mathrm{N}, 500\right.$ mbar) is indicated by the vertical arrows at the start of the instrumental data. Northern hemisphere ice core $\mathrm{CO}_{2}$ data are shown as single points (see caption for explanation). Error bars are estimated absolute values. For each set, the relative errors are less than the error bars shown. Also shown in Figure 6 (curve $c$ ) are the direct (chemically determined) air $\mathrm{CO}_{2}$ data (18901910, annual averages) obtained at the Montsouris Observatory, near Paris, France. The absolute values of the air sample data (as with some of the ice core data) do not appear to be those of a fully mixed atmosphere (see Discussion for results of forest fire plume transport modeling studies). Another set of chemical data from the north coast of France spanning 1872-1880 is also included in Figure 6 (data block $R$ ) because it is considered reliable [From and Keeling, 1986] within the plotted error range. (These data were obtained when 
there was an apparent recession in the PIAGREV, but because of the location, the samples also have a much higher probability of representing a fully mixed atmosphere).

In addition, Stuiver et al. [1984] provide a set of $\delta^{13} \mathrm{C}$ data and an atmospheric $\mathrm{CO}_{2}$ reconstruction together with a biospheric carbon flux curve which indicates a pulse injection of $\mathrm{CO}_{2}$ into the atmosphere for about a decade through $\mathrm{AD} 1900$. The $\mathrm{CO}_{2}$ reconstruction is qualitatively realistic from $\sim 1700$ to early 20 th century. Thereafter, the assumptions made in the Stuiver et al. model appear to break down. Fortuitously, the time of collection of the most reliable Montsouris (air) $\mathrm{CO}_{2}$ data occurred in this interval. The correspondence between these data and the other data presented earlier suggests strong coherence between the data sets and support for the second pulse in the PIAGREV signal. Lastly, because trace gas enrichment during the PIAGREV is seen in other trace gas data [Dibb et al., 1993], those data should be interpreted as supporting the PIAGREV. In particular, there are steps in methane and nitrous oxide in the Mount Logan and 20D cores in the interval 1850-1900. Both these gases are associated with biomass burning directly or with postburn soil gas emissions.

Next, we present a strategy involving a coupled atmosphere-ocean model, which was used in an effort to simulate the atmospheric $\mathrm{CO}_{2}$ variations over the last two centuries. This exercise requires a knowledge of the biomass "source" function and a certain freedom to construct carbon "sink" functions. An experimental, empirically determined, carbon input function was established after a series of iterations were carried out to produce a simulated $\mathrm{CO}_{2}$ curve that compared with the available data shown in Figure 6. Each iteration required a modification to the sink functions. While this procedure requires a significant degree of operator control (which involves manipulation of the model), the important point is that the atmospheric mixing ratios for $\mathrm{CO}_{2}$ in the high northern hemisphere latitude bands (where the data were obtained) is still dominated by the carbon input function rather than by the "inferred" sink functions. At the very least these sink functions could be used to guide experimental investigation of carbon sinks, which are still not properly understood.

\section{Global Carbon Cycle Model}

The time-dependent global carbon cycle model (GCCM) used in this study is a modified version of the model developed by Higuchi [1983a, b]. It describes the routing of $\mathrm{CO}_{2}$ injected into the atmosphere. As the overall structure of the model is essentially the same, only a short description is given here. The model is formulated to include, as much as is reasonably possible, the essential and fundamental processes of the global carbon cycle that are necessary to reproduce some of the globally consistent and basic features of the observed $\mathrm{CO}_{2}$ time series. The model structure is made up of three components: (1) an atmospheric model, which is two-dimensional, zonally averaged, and vertically layered; within this atmosphere, the air masses transport trace gases by advection and diffusion; (2) an oceanic model, with three explicitly resolved but independent water masses, all coupled to the atmosphere; (3) a terrestrial biosphere, which is treated as a lower boundary forcing function to the model atmosphere.

\section{Model Atmosphere}

The two-dimensional atmospheric model architecture is identical to the one used by Pearman and Hyson [1980] except that the present model is composed of 162 boxes (18 vertical columns, each column spanning a $10^{\circ}$ latitude band and composed of nine layers from the 1000-mbar surface to a 10-mbar upper level. The mass of the model atmosphere is $5.26 \times 10^{21} \mathrm{~g}$. The advective fluxes, $F_{i}$ ( $i=y, z$ where $y$ is meridional direction, $z$ is vertical direction), of $\mathrm{CO}_{2}$ (in units of concentration/unit time) are given by

$$
\begin{aligned}
& F_{y}^{A D V}=\left(\rho V C A_{H}\right) / M, \\
& F_{z}^{A D V}=\left(\rho W C A_{V}\right) / M,
\end{aligned}
$$

where $\rho$ is air density, $V$ and $W$ are the monthly averaged meridional and vertical wind speeds, respectively, $C$ is the $\mathrm{CO}_{2}$ concentration, $M$ is the mass of the atmospheric box under consideration, and $A_{H}$ and $A_{V}$ are the horizontal and vertical areas of the box, respectively, through which the gas flux takes place. Diffusion of the input $\mathrm{CO}_{2}$ is governed by the following diffusion equations:

$$
\begin{aligned}
& F_{y}^{D I F F}=\rho\left(K_{y y} \partial C / \partial y+K_{y z} \partial C / \partial z\right) A_{H} / M, \\
& F_{z}^{D I F F}=\rho\left(K_{z y} \partial C / \partial y+K_{z z} \partial C / \partial z\right) A_{V} / M,
\end{aligned}
$$

where $K_{i j}$ are diffusion coefficients. The eddy diffusion coefficients $(i=j)$ are always positive. The coefficients defined by $i \neq j$ are those introduced by Reed and German [1965] to account for the countergradient flux in the stratosphere. The seasonally stratified meridional winds were modified after Hyson et al. [1980] by Higuchi [1983a]. Vertical winds in a column were calculated using the mass conservation equation. The diffusion coefficients used were derived from krypton 85 data [Morimoto, 1994].

The rate of change of $\mathrm{CO}_{2}$ concentration in an atmospheric box is given by

$$
\Delta C / \Delta t=F_{y}^{A D V}+F_{z}^{A D V}+F_{y}^{D I F F}+F_{z}^{D I F F}
$$

The time step $\Delta t=1$ day for the atmospheric model.

The "box" model atmosphere is in contact with and coupled to the "box" model ocean, which will now be described. 


\section{Model Oceans}

The oceans constitute one of the two major internal reservoirs (the other being the land biosphere and, to a lesser but unknown degree, the ocean biosphere) which have any significant feedback to the anthropogenic $\mathrm{CO}_{2}$ in the atmosphere. The amount and the rate of absorption of excess atmospheric $\mathrm{CO}_{2}$ by the oceans depend on physical and chemical processes operating across the air-sea interface and at depth within the oceans.

The oceanic reservoir is represented by a model composed of three basins: the Atlantic, the Pacific, and the Indian. Each basin is treated as independent and is represented by a zonally averaged two-dimensional advective multibox model with a highly simplified meridional circulation pattern, which, however, resembles the gross water movement observed in nature [Broecker et al., 1980]. Carbon dioxide is transported in the direction of net water flow within a circulation cell. In each of the major oceans the surface layer (0- to 100-m depth), is divided into 11 zonally averaged boxes. (A single box represents the equatorial surface layer from $20^{\circ} \mathrm{N}$ to $20^{\circ} \mathrm{S}$ except for the Indian Ocean, where it is $0^{\circ}$ to $20^{\circ} \mathrm{S}$ ). Five more boxes are used to represent the intermediate layer water column down to $1000 \mathrm{~m}$. Thus there are a total of 16 boxes. Outside the equatorial regions box, the intermediate layer is not modeled explicitly. The deep ocean ( $>1000-\mathrm{m}$ depth) is also not treated explicitly. Since the turnover time of the deep water is of the order 500-1000 years, it is treated as an infinitely large sink for recent century-scale emissions of anthropogenic $\mathrm{CO}_{2}$.

Water fluxes for each surface box are determined from specified current speeds and from the vertical area of each box. Once the surface meridional fluxes are specified, all other fluxes are determined using the equations for conservation of mass. To produce downwelling and prevent upwelling of water into the extratropical surface layer, the poleward flowing meridional surface current in each of the model oceans is suitably specified [Higuchi, $1983 \mathrm{a}, \mathrm{b}]$. As an example of one of the parameters calculated from the model, the deep water flux upwelling in the equatorial region is $5.2 \times 10^{6} \mathrm{~m}^{3} / \mathrm{s}$.

The initial total carbon dioxide concentration $\sum \mathrm{C}_{0}$ is assigned to the surface layer of each ocean so that it increases poleward in accordance with a decreasing sea surface temperature scheme outlined in Table 2. In the same table the corresponding values of $\sum \mathrm{C}_{0}$ are also shown. The resultant latitudinal profile of $P_{m}$ (partial pressure of carbon dioxide in the mixed layer) is guided by the results given by Broecker et al. [1980]. The following values for the total borate concentration $\left(\sum B\right)$, carbonate-borate alkalinity constant $(A)$, and chlorinity $(C l)$, are used for all the oceans in calculating $P_{m}$ values: $\sum B=0.40$ per mil, $A=2.43$ per mil, and $C l$ $=19.24$ per mil.

The initial total carbon content in the surface layers is specified as $830 \times 10^{15} \mathrm{~g} \mathrm{C}$, which is about 1.4 times that of the initial atmospheric carbon mass of $610 \times 10^{15}$ $\mathrm{g} \mathrm{C}$ (corresponding to a mixing ratio for $\mathrm{CO}_{2}$ of about $280 \mathrm{ppm})$. Here we are only concerned with carbon in the form of carbon dioxide.

In the present model, the role of the marine biomass is not explicitly accounted for because of the large uncertainties in the processes that are involved.

In the coupling to the atmosphere the net flux, $\Delta F$, across the air-sea interface for wind speeds $w>3 \mathrm{~m} / \mathrm{s}$ [see Tans et al., 1990] is given by

$$
\Delta F=\mathrm{k}\left(P_{a}-P_{m}\right),
$$

where $P_{a}$ and $P_{m}$ are the $p \mathrm{CO}_{2}$ of the atmosphere and the mixed layer of the ocean, respectively. The parameter $\mathrm{k}$ is given (again following Tans et al. [1990]) by the equation

$$
\mathbf{k}=0.016(w-3)
$$

where $w$ is the horizontal wind speed at $10 \mathrm{~m}$ above the sea surface, in meters per second. Under steady state conditions, $\Delta F_{j}$ of box $j$ is made equal to the amount of carbon made deficient (or surplus) by the advective current in the surface layer. In addition, $\sum_{j=1}^{5} \Delta F_{j}+\sum_{j=7}^{11} \Delta F_{j}=\Delta F_{6}$ for each of the ocean basins, where the index 1 represents the most northern $\left(60^{\circ}-70^{\circ} \mathrm{N}\right)$ box, and the index 11 represents the most southern box $\left(60^{\circ}-70^{\circ} \mathrm{S}\right)$. The equatorial and largest box is represented by the index 6 .

The model of Nir and Lewis [1975] is employed in transporting carbon dioxide from the extratropical surface layer into the intermediate layer and finally into the equatorial column. The time step used in the ocean model is 1 year. The residence time in the intermediate layer is defined here as the time which $\mathrm{CO}_{2}$ spends in transit between the surface layer and the equatorial column. The residence times of excess $\mathrm{CO}_{2}$ in the in-

Table 2. Temperature and Carbon Data Used in Model Oceans

\begin{tabular}{ccc}
\hline $\begin{array}{c}\text { Latitude Zone, } \\
\text { deg }\end{array}$ & $\begin{array}{c}\text { Sea Surface } \\
\text { Temperature, }{ }^{\circ} \mathrm{C}\end{array}$ & $\begin{array}{c}\text { Total Initial Carbon Concentration } \\
\sum \mathrm{C}_{o}, \mathrm{~mol} / \mathrm{cm}^{3}\end{array}$ \\
\hline $0-20$ & 28 & 2.00 \\
$20-30$ & 23 & 2.02 \\
$30-40$ & 18 & 2.04 \\
$40-50$ & 12 & 2.07 \\
$50-60$ & 7 & 2.14 \\
$60-70$ & 3 & 2.17 \\
\hline
\end{tabular}


termediate layer range from 30 years for downwelling in low latitudes to 100 years for downwelling in high latitudes. Carbon advected into the deep water is treated in this modeling exercise as carbon lost from the cycle.

The ocean model is calibrated with observed vertical profiles of prebomb ${ }^{14} \mathrm{C}$ data [Bien et al., 1960; Broecker et al., 1960] and compared with results obtained by Bjorkstrom [1979]. The atmospheric production rate of ${ }^{14} \mathrm{C}$ atoms by cosmic rays is assumed to be constant at 2 atoms $/ \mathrm{cm}^{2} / \mathrm{s}$. Given the observed surface values of ${ }^{14} \mathrm{C} /{ }^{12} \mathrm{C}$, the ocean model is able to simulate $\Delta^{14} \mathrm{C}$ values and hence $C^{14}$ ages, relative to the surface layer, of over 200 years for the deep water upwelling into the Atlantic equatorial column, and over 1000 years for the deep water upwelling into the Pacific equatorial column.

\section{Model Carbon Budget and Comparison Between} This and Other GCCMs

The overall carbon budget in the model is balanced for each time step. For example, in the 1985 simulation the following idealized input (in $\mathrm{Gt} / \mathrm{yr}$ ) was applied: fossil fuel input $=5.5$; tropical biomass input $=2.0\left(\sum\right.$ $=+7.5 \mathrm{Gt} / \mathrm{yr})$. The following sinks were calculated: atmospheric reservoir $=3.0$; ocean sink $=2.0$. To balance the budget, a northern hemisphere midlatitude (land) sink $=2.5$ was introduced $\left(\sum=-7.5 \mathrm{Gt} / \mathrm{yr}\right)$. This produces a "model" northern hemisphere-southern hemisphere latitudinal gradient of about $5 \mathrm{ppm}$, whereas the observed value is about $4 \mathrm{ppm}$. Comparing these results with Tables 1.1 and 1.3 in Intergovernmental Panel on Climate Change [1994], it may be seen that the GCCM described here is broadly consistent with other carbon cycle models. The main difficulty for all these models is to account for all the carbon sinks. It has been recognized that both northern and southern hemisphere sink fluxes can change quite significantly on an interannual timescale (especially the southern hemisphere, where a $300 \%$ subdecadal change has been postulated in order to explain variations in the data) [Conway et al., 1994]. The mechanisms of these variations are not properly understood.

In the model simulation to examine the atmospheric effects of the PIAGREV, the model was started in AD 1800. The biomass carbon input function (described in the next section) was applied. Empirical sink functions were constructed in order to replicate, as nearly as possible, the atmospheric $\mathrm{CO}_{2}$ curve for high southern latitudes obtained from Antarctic ice cores.

\section{Biomass Carbon Input Function}

The biospheric carbon function shown in Figure 5 (curve 4) was created from an initial estimated function using a successive trial procedure. We manually created the trial function with an amplitude equal to the function derived by Peng and Freyer [1986] and with a shape that reflected the two peaks in activity of the PIAGREV as seen in our own ice core data. Because the GCCM is zonally averaged, the carbon input function does not discriminate between emissions that came from North America, Europe, or Eurasia. This initial function was input to the GCCM over a prescribed northern hemisphere midlatitude band $\left(40^{\circ}\right.$ to $\left.60^{\circ} \mathrm{N}\right)$, and the output (atmospheric $\mathrm{CO}_{2}$ concentrations at high northern hemisphere latitudes) was examined. It was necessary, at this stage to modify the sink functions so that the Antarctic ice core $\mathrm{CO}_{2}$ data could be matched. These data are assumed to closely represent the concentrations of $\mathrm{CO}_{2}$ in the remote atmosphere of the southern hemisphere. By progressively increasing the amplitude of the initial carbon input function, it was possible to observe the corresponding increase in atmospheric $\mathrm{CO}_{2}$ in the northern hemisphere. Each step required an adjustment of the sink function structure in order to duplicate the high-latitude southern hemisphere ice core data. Details of this function and a sensitivity analysis of the model will be described in a paper in preparation by K. Higuchi. This study of the time variation of atmospheric $\mathrm{CO}_{2}$ over the last two centuries is quite limited by deficiencies in knowledge about the physics and distribution of carbon sinks [Tans et al., 1990; Quay et al., 1992]. Here, as in any other long-term (century-scale) carbon cycle studies, estimated empirical sink functions have to be used.

The biospheric carbon function (curve 4) shown in Figure 5 was the last of a series of trial functions. It still produces less total cumulative carbon flux into the atmosphere than curve 1 (in Fig. 5), which set the upper limit of our trials. Even so, curve 4 produces a 5-10 ppmv increase above the Antarctic curve between about 1850 and 1920, as can be seen in Figure 6. The output curve $d$ is considered to possess similarities to the available data in a qualitative sense. Further manipulation of the carbon input function and the sink function was not pursued as this was not considered to be in the best interests of this exercise. Rather, the main point is that it is possible to generate, in this model, elevated levels of $\mathrm{CO}_{2}$ mixing ratio in the high-latitude northern hemisphere that are relatively insensitive to the structure of the more southerly sinks, whose architecture is necessarily of an empirical nature, when the only "calibration" of the model output for the high southern latitudes is the Antarctic ice core data.

The simplified physical ocean sink mechanism in the original model [Higuchi, 1983b] was found to be inadequate; that is, not enough gas is absorbed by the model ocean. Subsequently, it has been found that there are other processes [e.g., Farmer et al., 1993] operating at the air-ocean interface that enhance the absorption. Also, we are ignoring the possibility that the oceans have undergone decadal-scale circulation changes. Such changes could have affected atmospheric $\mathrm{CO}_{2}$ levels in a similar way that oceanic El Niño's affect atmospheric $\mathrm{CO}_{2}$. There is some preliminary observational evidence to suggest that deep water formation in the North Atlantic (Greenland Sea) has slowed down in recent years. A recent global carbon model [Kwon and Schnoor, 1994] is similarly limited with respect to sink structure.

In Figure 6, it is to be noted that peaks in the simulated $\mathrm{CO}_{2}$ curve $d$ show a lag with respect to peaks in the forcing function of the model northern hemisphere 
atmosphere. Without a suitably prescribed additional sink to the south, Antarctic atmospheric $\mathrm{CO}_{2}$ concentrations would closely follow the northern hemisphere, with a lag of between 1 and 2 years [see also Keeling et al., 1989]. Carbon forcing functions in the northern hemisphere midlatitudes and tropics after $\sim 1950$ are designed to replicate, in the model, the high-latitude northern hemisphere instrumental data as well as to be consistent with various estimates of biomass burning [e.g., Peng and Freyer, 1986]. The important features of curve $d$ are the twin maxima between 1850 and 1950 , which clearly reflect the assumed biomass forcing function. The difference between curves $a$ and $d$ defines a possible transient interhemispheric gradient that might have been similar to the present one, on a timescale of decades, during the late 19th century.

The current maximum interhemispheric (approximate pole to pole) difference in $\mathrm{CO}_{2}$ mixing ratio is 3-4 ppmv [Conway et al., 1988; Tanaka et al., 1988; Keeling et al., 1989], whereas its value in 1957 was close to $1 \mathrm{ppmv}$ [Keeling et al., 1989] (see Fig. 6). The value before the start of instrumental measurements is not known with any certainty but has generally been assumed to be negligible (other model studies included a much smaller biomass input function than we have used). However, in the light of the data presented here, this does not appear to have been the case. For future, more precise, model simulations it is of interest to know whether the past difference between the $\mathrm{CO}_{2}$ mixing ratios of the high-latitude northern and southern hemisphere atmospheres could have been similar to or greater than the present value.

\section{Discussion of Results and Conclusions}

Given that the PIAGREV signature in the ice cores is a result of the "fallout" of biomass burn products transported over long distances, we can make use of a large literature base upon which to develop a discussion of some of the dynamics of the processes involved [e.g., Levine, 1991]. From the purely meteorological standpoint the recently developed concept of "tropospheric rivers," or filaments of water vapor in the troposphere [Newell et al., 1992; Newell and Zhu, 1994], appears to offer a useful avenue for discussing the dynamics of long-range transport of surface emissions associated with agrarian activities. It is possible that smoke plumes from major fires in North America may have formed similar "filaments" of aerosols in the atmosphere, even in association with the filaments of water vapor, which appears to have the capacity to form an aerosol with $\mathrm{CO}_{2}$. This has a bearing on some of the anomalously high ice core $\mathrm{CO}_{2}$ data presented earlier. (There is some basis for supposing that solid rime ice derived from supercooled water vapor droplets is enriched in $\mathrm{CO}_{2}$. Rime ice has been found infrequently at high altitudes on Mount Logan.)

The time-dependent evolution of forest fire smoke plumes that has been simulated in a numerical atmospheric transport model by Iacobellis et al. [1994] also provides possible answers to the question of the transient $\mathrm{CO}_{2}$ values seen in northern hemisphere ice cores and to the hitherto unexplained irregularities existing between different tree $\delta^{13} \mathrm{C}$ time series. Using the biomass $\mathrm{CO}_{2}$ emissions for 1900 derived in this paper (input function in Fig. 5) and applying them to midlatitude North America during the PIAGREV, recent simulations by S. Iacobellis (unpublished data, 1995) indicate that "excess" $\mathrm{CO}_{2}$ gas concentrations of 2-4 ppmv above background could have reached parts of the high Canadian Arctic, Greenland, and Europe and persisted on the timescale of 1 month. The simulations made so far use only the 1979 global wind data set. For extreme meridional airflow, significantly elevated levels of $\mathrm{CO}_{2}$ could have impacted distant tree stand and ice core sites to produce the anomalies that are seen in the data.

An example of a visible smoke layer in close proximity to the ice core site in the St. Elias Mountains is described by Benjey [1974]. The smoke pall was seen in late June 1969, and it was estimated by pilots to have a ceiling of around $5000 \mathrm{~m}$ against Mount Logan. This smoke originated from forest fires burning along the Alaska-Yukon border. In August 1986 the first author saw a similar brown smoke layer (approximately $1.5 \mathrm{~km}$ thick), which was attributed to forest fires in Alaska. The ceiling then was at least $5000 \mathrm{~m}$ altitude. Although of a regional scale, these observations serve to reinforce the conjecture that unmixed forest fire emissions may impact ice core sites in the northern hemisphere.

The collected northern hemisphere $\mathrm{CO}_{2}$ data suggest that concentrations of this trace gas may have significantly exceeded southern hemisphere values (by several ppmv) at certain times and for brief seasonal periods at the ice core sites. These northern hemisphere highlatitude $\mathrm{CO}_{2}$ levels (elevated by several ppmv) could have been seasonally sustained on the timescale of a decade, which is the timescale of the PIAGREV. The possibility was already considered by Siegenthaler et al. [1988] that atmospheric $\mathrm{CO}_{2}$ levels may have increased significantly, albeit temporarily, before the extensive use of fossil fuels. However, these data, which came from a south pole core, have not been substantiated from additional Antarctic cores or from Greenland core studied so far.

The GCCM modeling suggests that the higher $\mathrm{CO}_{2}$ values plotted in Figure 6 do not represent fully mixed northern hemisphere atmospheric annual values, but nevertheless they can be considered to be acting as tracers for biomass burning. Similarly, certain trees throughout the northern hemisphere would have responded to regional (and seasonal) climatic variations and to smoke assimilation according to atmospheric circulation at the time. Certain trees only form new wood for very brief periods, with timing determined by local climatic conditions. This could account for much of the nonuniformity seen in the late 19th century tree ring data.

The atmospheric modeling results reported here indicate that the maximum short-term interhemispheric 
$\mathrm{CO}_{2}$ difference (the north-south gradient) might have equaled or slightly exceeded the present value, although this modeling is not highly constrained. Nevertheless, the modeling results do support the atmospheric $\mathrm{CO}_{2}$ data in several important aspects. The structure and results of the GCCM used here also suggest that carbon cycle models should be improved by incorporating better physical mechanisms into the carbon sinks [e.g., Robertson and Watson, 1992; Farmer et al, 1993] so that current semi-empirical or quasi-arbitrary methods of model tuning may be reduced in the future. Also, in modeling the carbon cycle through the PIAGREV, the effects of possible atmospheric and oceanic cooling should be accounted for.

There are other trace gases that may be used as indicators of biomass burning. Methane and nitrous oxide concentration data for Mount Logan [Dibb et al., 1993] are smoothly varying and marginally suggest (as does the $\mathrm{CO}_{2}$ data) small increases $\sim 1860$. The more anthropogenically sensitive southern Greenland (20D) core [Dibb et $a l ., 1993$ ] shows consistently elevated levels of methane during the late 19th century. These collected data offer qualitative supporting evidence for biomass fire activity [Laursen et al., 1992; Levine et al., 1992] in North America. Furthermore, the implications of biomass burning for global climate variations are now well known.

It appears that associated factors, such as surface albedo changes and atmospheric dust and smoke [Sagan et al., 1979], causing local cooling (at least in the northern hemisphere) temporarily negated any tendency for radiative gas greenhouse warming. As a result, the PIAGREV, through the influence of smoke plumes [Pittock et al., 1988; Penner et al., 1991] and associated agricultural dust, may have helped deepen and prolong the ending of the Little Ice Age [Grove, 1988], which is recognized to have occurred in many glaciated alpine regions. Documentation of the northern hemisphere regional climatic regimes throughout the PIAGREV will be the subject of a paper in preparation.

Acknowledgments. We acknowledge support from Environment Canada (National Hydrology Research Institute and the Atmospheric Environment Service), the Electric Power Research Institute of California, the U.S. National Science Foundation, Natural Sciences and Engineering Research Council of Canada, and the Arctic Institute of North America, University of Calgary. We also thank J.-M. Barnola for providing the Mount Logan ice core $\mathrm{CO}_{2}$ data and $\mathrm{D}$. Raynaud and C. Lorius (CNRS, Grenoble) for supporting the collaboration. J.E. Dibb, M.J. Spencer, and S. Whitlow helped in data interpretation and A.T. Wilson, C.S. Wong, J.-M. Barnola, M. Stuiver, and S.W. Leavitt read earlier versions of the manuscript and offered many helpful suggestions. L.J. Toolin and C.J. Eastoe kindly read the final manuscript and noted that their unpublished $\delta^{13} \mathrm{C}$ record for C4 grasses from the American Southwest appeared to corroborate at least the $\mathrm{NH}_{4}^{+}$record in Figure 1 for the late 19th century. We thank the journal reviewers and the editor (J. Penner) for helpful advice and detection of obscure statements and for overall improvement to the paper. We also acknowledge F.O. Smith for editing and document preparation. Acknowledgement of individuals does not imply that they necessarily agree with all our interpretations of the data.

\section{References}

Alford, D., and C. Keeler, Stratigraphic studies of the winter snow layer, Mount Logan, St. Elias Range, in Icefield Ranges Research Project, Scientific Results, vol. 2, edited by V. Bushnell and R. H. Ragle, pp. 37-42, Am. Geogr. Soc., New York, and Arctic Inst. N. Am., Montreal, 1970.

Benjey, W. G., The effects of forest-fire smoke on insolation in the St. Elias Mountains, in Icefield Ranges Research Project, Scientific Results, vol. 4, edited by V. Bushnell and M. G. Marcus, pp. 129-131, Am. Geogr. Soc., New York, and Arctic Inst. N. Am., Montreal, 1974.

Benson, C. S., Stratigraphic studies in the snow and firn of the Greenland Ice Sheet, Research Report 70, 93 pp., Snow, Ice, Permafrost Res. Establ., Wilmette, Ill., 1962.

Bien, G. S., N. W. Rakestraw, and H. E. Suess, Radiocarbon concentration in Pacific Ocean water, Tellus, 12, 436-443, 1960.

Bischof, W., The $\mathrm{CO}_{2}$ content of the upper polar troposphere between 1963 and 1979, in Carbon Cycle Modelling, Scope, vol. 16, edited by B. Bolin, pp. 113-116, John Wiley, New York, 1981.

Bjorkstrom, A., A model of $\mathrm{CO}_{2}$ interaction between atmosphere, oceans and land biota, in The Global Carbon Cycle, Scope, vol. 13, edited by B. Bolin, E. T. Degens, S. Kempe, and P. Ketner, pp. 403-457, John Wiley, New York, 1979.

Broecker, W. S., R. Gerard, M. Ewing, and B. Heezen, Natural radiocarbon in the Atlantic Ocean, J. Geophys. Res., 65, 2903-2931, 1960.

Broecker, W. S., T.-H. Peng, and R. Engh, Modelling the carbon system, in Carbon Dioxide Effects Research and Assessment Program, edited by L. E. Schmitt, Proc. Carbon Dioxide Clim. Res. Program Conf., 11, 43-99, 1980.

Chatfield, C., Statistics for Technology, 3rd ed., Chapman and Hall, New York, 1983.

Chylek, P., B. Johnson, and H. Wu, Black carbon concentration in a Greenland Dye-3 ice core, Geophys. Res. Lett., 19, 1951-1953, 1992.

Claud, C., Analyse du $\mathrm{CO}_{2}$ contenu dans les bulles d'au piegees dans la glace du Mont Logan (Yukon, Canada), Mem. Lab. Glaciol. Geophys. Environ., 67 pp., CNRS, Grenoble, France, 1985.

Conway, T. J., P. P. Tans, L. S. Waterman, K. W. Thoning, K. A. Masarie, and R. H. Gammon, Atmospheric carbon dioxide measurements in the remote global troposphere, 1981-1984, Tellus, 40B, 81-115, 1988.

Conway, T. J., P. P. Tans, L. S. Waterman, K. W. Thoning, D. R. Kitzis, K. A. Masarie, and N. Zhang, Evidence for interannual variability of the carbon cycle from the $\mathrm{Na}$ tional Oceanic and Atmospheric Administration/Climate Monitoring and Diagnostics Laboratory Global Air Sampling Network, J. Geophys. Res., 99, 22,831-22,855, 1994.

Delmas, R. J., A natural artifact in Greenland ice core $\mathrm{CO}_{2}$ measurements, Tellus, 45B, 391-396, 1993.

Dibb, J. E., J. L. Jaffrezo, and M. Legrand, Initial findings of recent investigations of air-snow relationships in the summit region of the Greenland Ice Sheet, J. Atm. Chem., 14, 167-180, 1992.

Dibb, J. E., R. A. Rasmussen, P. A. Mayewski, and G. Holdsworth, Northern hemisphere concentrations of methane and nitrous oxide since 1800: Results from the Mount Logan and 20D ice cores, Chemosphere, 27, 24132423, 1993.

Enting, I. G. The incompatibility of ice core $\mathrm{CO}_{2}$ data with reconstructions of biotic $\mathrm{CO}_{2}$ sources, II, The influence of $\mathrm{CO}_{2}$ fertilized growth, Tellus, 44B, 23-32, 1992.

Etheridge, D. M., L. P. Steele, R. L. Langenfelds, R. J. Francey, J.-M. Barnola, and V. I. Morgan, Natural and anthropogenic changes in atmospheric $\mathrm{CO}_{2}$ over the last 
1000 years from air in Antarctic ice and firn, J. Geophys. Res., 101, 4115-4128, 1996.

Farmer, D. M., C. L. McNeil, and B. D. Johnson, Evidence for the importance of bubbles in increasing air-sea gas flux, Nature, 361, 620-623, 1993.

Francey, R. J., Tasmanian tree rings belie suggested anthropogenic ${ }^{13} \mathrm{C} /{ }^{12} \mathrm{C}$ trends, Nature, 290, 232-235, 1981.

Francey, R. J., and G. D. Farquhar, An explanation of ${ }^{13} \mathrm{C} /{ }^{12} \mathrm{C}$ variations in tree rings, Nature, 297, 28-31, 1982.

Freyer, H. D., Preliminary evaluation of past $\mathrm{CO}_{2}$ increase as derived from ${ }^{13} \mathrm{C}$ measurements in tree rings, in Carbon Dioxide, Climate and Society, edited by J. Williams, pp. 69-77, Pergamon, New York, 1978.

Freyer, H. D., On the ${ }^{13} \mathrm{C}$ record in tree rings, $\mathrm{I},{ }^{13} \mathrm{C}$ variations in northern hemispheric trees during the last 150 years, Tellus, 31, 124-137, 1979.

Freyer, H. D., Interpretation of the northern hemisphere record of ${ }^{13} \mathrm{C} /{ }^{12} \mathrm{C}$ trends of atmospheric $\mathrm{CO}_{2}$ in tree rings, in The Changing Carbon Cycle: A Global Analysis, edited by J. R. Trabalka and D. E. Reichle, Pp. 125-150, Springer-Verlag, New York, 1986.

Freyer, H. D., and N. Belacy, ${ }^{13} \mathrm{C} /{ }^{12} \mathrm{C}$ records in northern hemispheric trees during the past 500 years-Anthropogenic impact and climatic superpositions, J. Geophys. Res., 88, 6844-6852, 1983.

Friedli, H., H. Lötscher, H. Oeschger, U. Siegenthaler, and B. Stauffer, Ice core record of the ${ }^{13} \mathrm{C} /{ }^{12} \mathrm{C}$ ratio of atmospheric $\mathrm{CO}_{2}$ in the past two centuries, Nature, 324, 237$238,1986$.

From, E., and C. D. Keeling, Reassessment of late 19th century atmospheric carbon dioxide variations in the air of western Europe and the British Isles based on an unpublished analysis of contemporary air masses by G. S. Callendar, Tellus, 38B, 87-105, 1986.

Gould, D. F., Beyond the Shining Mountains, Binsford and Mort, Portland, Or., 1938.

Grove, J. M., The Little Ice Age, Methuen, New York, 1988.

Higuchi, K., A global carbon cycle model, Ph.D. dissertation, Univ. of Toronto, Ontario, Canada, 1983a.

Higuchi, K., Effect of two different atmospheric models on the absorptive rate of excess atmospheric carbon by the sea, Geophys. Res. Lett., 1O(9), 869-872, $1983 \mathrm{~b}$.

Holdsworth, G., H. R. Krouse, and M. Nosal, Ice core climate signals from Mount Logan, Yukon, A.D. 1700-1987, in Climate Since $A D 1500$, edited by R. S. Bradley and P. D. Jones, pp. 483-504, Routledge, New York, 1992.

Hyson, P., P. J. Fraser, and G. I. Pearman, A two-dimensional transport simulation model for trace atmospheric constituents, J. Geophys. Res., 85, 4443-4455, 1980.

Iacobellis, S. F., R. Frouin, H. Razafimpanilo, and R. C. J. Somerville, Biomass burning in the savannas of North Africa and atmospheric carbon dioxide, J. Geophys. Res., 99, 8321-8334, 1994

Intergovernmental Panel on Climate Change, Climate change 1994: Radiative forcing of climate change and an evaluation of the IPCC 1992 emission scenarios, edited by J. T. Houghton, L. G. Meira Filho, J. Bruce, H. Lee, B. A. Callander, E. Haites, N. Harris, and K. Maskell, 339 pp., Cambridge Univ. Press, Cambridge, New York, 1994.

Junge, C. E. Air Chemistry and Radioactivity, Academic, San Diego, Calif., 1963.

Keeling, C. D., Industrial production of carbon dioxide from fossil fuel and limestone, Tellus, 25, 1174-1198, 1973.

Keeling, C. D., R. B. Bacastow, A. F. Carter, S. C. Piper, T. P. Whorf, M. Heimann, W. G. Mook, and H. Roeloffzen, A three-dimensional model of atmospheric $\mathrm{CO}_{2}$ transport based on observed winds, 1, Analysis of observational data, in Aspects of Climate Variability in the Pacific and the Western Americas, edited by D. H. Peterson, pp. 165236, AGU, Washington, D. C., 1989.

Kwon, O.-Y., and J. L. Schnoor, Simple global carbon model: The atmosphere-terrestrial biosphere-ocean interaction, Global Biol. Cycles, 8(3), 295-306, 1994.

Labelle, J., Snow studies at high elevations, Mount Logan, Yukon, in Icefield Ranges Research Project, Scientific Results, vol. 4, edited by V. Bushnell and M. G. Marcus, pp. 211-218, Am. Geogr. Soc. and Arct. Inst. N. Am., 1974.

Laursen, K. K., P. V. Hobbs, L. F. Radke, and R. A. Rasmussen, Some trace gas emissions from North American biomass fires with an assessment of regional and global fluxes from biomass burning, J. Geophys. Res., 97, 20,687$20,701,1992$.

Leavitt, S. W., The Great Lakes forest fires of 8-10 October, 1871, pp. 519-522, in Global Biomass Burning, edited by J. S. Levine, MIT Press, Cambridge, Mass., 1991.

Leavitt, S. W., Environmental information from ${ }^{13} \mathrm{C} /{ }^{12} \mathrm{C}$ ratios of wood, in Climate Change in Continental Isotopic Records, Geophys. Monogr. Ser., vol. 78, pp. 325331, AGU, Washington, D. C., 1993.

Leavitt, S. W., and A. Long, Altitudinal differences in $\delta^{13} \mathrm{C}$ of Bristlecone Pine tree rings, Naturwissenschaften, 79, 178-180, 1992.

Legrand, M., M. DeAngelis, T. Staffelbach, A. Neftel, and B. Stauffer, Large perturbations of ammonium and organic acids content in the summit-Greenland ice core, Geophys. Res. Lett., $19(5)$, 473-475, 1992.

Levine, J. S. (Ed.), Global Biomass Burning, MIT Press, Cambridge, Mass., 1991.

Levine, J. S., W. S. Cofer III, D. I. Sebacher, R. P. Rhinehart, E. L. Winstead, S. Sebacher, C. R. Hinkle, P. A. Schmaltzer, and A. M. Koller Jr., The effects of fire on biogenic emissions of methane and nitric oxide from wetlands, J. Geophys. Res., 95, 1853-1864, 1992.

Marland, G., Fossil fuels $\mathrm{CO}_{2}$ emissions, CDIAC Communications, Winter 1989, pp. 1-3, Carbon Dioxide Inf. Anal. Cent., Oak Ridge Natl. Lab., Oak Ridge, Tenn., 1989.

Marland, G., and R. M. Rotty, Carbon dioxide emissions from fossil fuels: A procedure for estimation and results for 1950-1982, Tellus, 36B, 232-261, 1984.

Marland, G., T. A. Boden, R. C. Griffin, S. F. Huang, P. Kanciruk, and T.R. Nelson, Estimates of $\mathrm{CO}_{2}$ emissions from fossil fuel burning and cement manufacturing, based on the United Nations Energy Statistics and U.S. Bureau of Mines cement manufacturing data, NDP-030, Oak Ridge Natl. Lab., Oak Ridge, Tenn., 1989.

Mayewski, P. A., W. B. Lyons, M. J. Spencer, M. Twickler, C. F. Buck, and S. I. Whitlow, An ice core record of atmospheric response to anthropogenic sulphate and nitrate, Nature, 346, 554- 556, 1990.

Mayewski, P. A., L. D. Meeker, M. C. Morrison, M. S. Twickler, S. I. Whitlow, K. K. Ferland, D. A. Meese, M. R. Legrand, and J. P. Steffensen, Greenland ice core "signal" characteristics: An expanded view of climate change, J. Geophys. Res., 98, 12,839- 12,847, 1993.

Morimoto, S., A study of the carbon cycle on the earth's surface from measurements of the carbon isotope ratio of atmospheric $\mathrm{CO}_{2}$, Ph.D. thesis, Tohoku Univ., Sendai, Japan, 1994.

Neftel, A., H. Friedli, E. Moor, H. Lötscher, H. Oeschger, U. Siegenthaler, and B. Stauffer, Historical $\mathrm{CO}_{2}$ record from the Siple Station ice core, edited by T. A. Boden, D. P. Kaiser, R. J. Sepanski, and F. W. Stoss, pp. 11-14, in Trends '93: A Compendium of Data on Global Change, ONRL/CDIAC-65, Carbon Dioxide Inf. Anal. Cent., Oak Ridge Natl. Lab., Oak Ridge, Tenn., 1994.

Newell, R. E., and Y. Zhu, Tropospheric rivers: A one year record and a possible application to ice core data, Geophys. Res. Lett., 21, 113-116, 1994.

Newell, R. E., N. E. Newell, Y. Zhu, and C. Scott, Tropospheric rivers?-A pilot study, Geophys. Res. Lett., 12(24), 2401-2404, 1992. 
Nir, A., and S. Lewis, On tracer theory in geophysical systems in the steady and nonsteady state, I, Tellus, 27, 372-383, 1975.

Pearman, G. I., and P. Hyson, Activities of the global biosphere as reflected in atmospheric $\mathrm{CO}_{2}$ records, J. Geophys. Res., 85, 4468-4474, 1980.

Peng, T.-H., and H. Freyer, Revised estimates of atmospheric $\mathrm{CO}_{2}$ variations based on the tree-ring ${ }^{13} \mathrm{C}$ record, in The Changing Carbon Cycle: A Global Analysis, edited by J. R. Trabalka and D. E. Reichle, pp. 151-159, SpringerVerlag, New York, 1986.

Peng, T-H., W. S. Broecker, H. D. Freyer, and S. Trumbore, A deconvolution of the tree rings based $\delta^{13} \mathrm{C}$ record, $J$. Geophys. Res., 88, 3609-3620, 1983.

Penner, J. E., S. J. Ghan, and J. J. Walton, The role of biomass burning in the budget and cycle of carbonaceous soot aerosols and their climate impact, in Global Biomass Burning, edited by J. S. Levine, MIT Press, Cambridge, Mass., 1991.

Pittock, A. B., J. S. Frederiksen, J. R. Garratt, and K. Walsh, Climatic effects of smoke and dust produced from nuclear conflagrations, in Aerosols and Climate, edited by P. V. Hobbs and M. P. McCormick, pp. 395-410, A. Deepak, Hampton, Va., 1988.

Quay, P. D., B. Tilbrook, and C. S. Wong, Oceanic uptake of fossil fuel $\mathrm{CO}_{2}$ : Carbon-13 evidence, Science, 256, 74-79, 1992.

Raynaud, D., and J. M. Barnola, An Antarctic ice core reveals atmospheric $\mathrm{CO}_{2}$ variations over the past few centuries, Nature, 315, 309-311, 1985.

Reed, R., and K. German, A contribution to the problem of stratospheric diffusion by large scale mixing, Mon. Weather Rev., 93, 313-321, 1965.

Robertson, J. E., and A. J. Watson, Thermal skin effect of the surface ocean and its implications for $\mathrm{CO}_{2}$ uptake, Nature, 358, 738-740, 1992.

Sagan, C., O. B. Toon, and J. B. Pollack, Anthropogenic albedo changes and earth's climate, Science, 206, 13631368, 1979.

Schwander, J., The transformation of snow to ice and the occlusion of gases, in The Environmental Record in Glaciers and Ice Sheets, edited by H. Oeschger and C. C. Langway, pp. 53-67, John Wiley, New York, 1989.

Siegenthaler, U., 19th century measurements of atmospheric $\mathrm{CO}_{2}-\mathrm{A}$ comment, Clim. Change, 6, 409-411, 1984.

Siegenthaler, U., and $\mathrm{H}$. Oeschger, Biospheric $\mathrm{CO}_{2}$ emissions during the past 200 years reconstructed by deconvolution of ice core data, Tellus, 39B, 140-154, 1987.

Siegenthaler, U., H. Friedli, H. Loetscher, E. Moor, A. Neftel, H. Oeschger, and B. Stauffer, Stable-isotope ratios and concentration of $\mathrm{CO}_{2}$ in air from polar ice cores, $A n n$. Glaciol., 10, 151-156, 1988.

Staffelbach, T., B. Stauffer, A. Sigg, and H. Oeschger, $\mathrm{CO}_{2}$ measurements from polar ice cores: More data from different sites, Tellus, 43B, 91-96, 1991.

Stanhill, G. The Montsouris series of carbon dioxide concentration measurements 1877-1910, Clim. Change, 4, 221$237,1982$.

Stanhill, G., Reply with some additional details on 'The Montsouris series of carbon dioxide concentration measurements, 1877-1910', Clim. Change, 5, 417-419, 1983.

Stanhill, G., A further reply concerning the accuracy of 'The Montsouris series of carbon dioxide concentration measurements, 1877-1910', Clim. Change, 6, 413-415, 1984.
Staufter, B., A. Neftel, H. Oeschger, and J. Schwander, $\mathrm{CO}_{2}$ concentration in air extracted from Greenland ice samples, in Greenland Ice Core: Geophysics, Geochemistry, and the Environment, edited by C. C. Langway Jr., H. Oeschger, and W. Dansgaard, Geophys. Monogr. Ser., vol. 33, pp. 85-89, AGU, Washington, D. C., 1985.

Stuiver, M., Ancient carbon cycle changes derived from treering ${ }^{13} \mathrm{C}$ and ${ }^{14} \mathrm{C}$, in The Changing Carbon Cycle: $A$ Global Analysis, edited by J. R. Trabalka and D. E. Reichle, pp. 109-124, Springer-Verlag, New York, 1986.

Stuiver, M., and T.F. Braziunas, Tree cellulose ${ }^{13} \mathrm{C} /{ }^{12} \mathrm{C}$ isotope ratios and climatic change, Nature, 328, 58-60, 1987.

Stuiver, M., R. L. Burk, and P. D. Quay, ${ }^{13} \mathrm{C} /{ }^{12} \mathrm{C}$ ratio in tree rings and the transfer of biospheric carbon to the atmosphere, J. Geophys. Res., 89, 11,731-11,748, 1984.

Tanaka, M., T. Nakazawa, S. Aoki, and H. Ohshima, Aircraft measurements of tropospheric carbon dioxide over the Japanese Islands, Tellus, 4OB, 16-22, 1988.

Tans, P. P., and W. G. Mook, Past atmospheric $\mathrm{CO}_{2}$ levels and the ${ }^{13} \mathrm{C} /{ }^{12} \mathrm{C}$ ratios in tree rings, Tellus, 32, 268-283, 1980 .

Tans, P. P., I. Y. Fung, and T. Takahashi, Observational constraints on the global atmospheric $\mathrm{CO}_{2}$ budget, Science, 247, 1431-38, 1990.

Wahlen, M., D. Allen, B. Deck, and A. Herchenroder, Initial measurements of $\mathrm{CO}_{2}$ concentrations (1530 to 1940 AD) in air occluded in the GISP2 ice core from central Greenland, Geophys. Res. Lett., 18(8), 1457-60, 1991.

Waterman, L. S., Comments on 'The Montsouris series of carbon dioxide concentration measurements, 1877-1910', by G. Stanhill, Clim. Change, 5, 413-415, 1983.

Whitlow, S. I., P. A. Mayewski, G. Holdsworth, M. S. Twickler, and J. E. Dibb, An ice core based record of biomass burning in the arctic and subarctic, 1750-1980, Tellus, 46B, 234-242, 1994.

Wigley, T. M. L., The pre-industrial carbon dioxide level, Clim. Change, 5, 315-320, 1983.

Wilson, A. T., Pioneer agriculture explosion and $\mathrm{CO}_{2}$ levels in the atmosphere, Nature, 273, 40-41, 1978.

Wong, C. S., Atmospheric input of carbon dioxide from burning wood, Science, 200, 197-200, 1978.

G. Holdsworth, The Arctic Institute of North America, University of Calgary, Alberta, Canada T2N 1N4 (email: gholdswo@acs.ucalgary.ca).

K. Higuchi, Atmospheric Environment Service, Department of the Environment, Downsview, Ontario, Canada M3H 5T4 (email: khiguchi@cid.aes.doe.ca).

P.A. Mayewski and G.A. Zielinski, Glacier Research Group, Institute for the Study of Earth, Oceans and Space, University of New Hampshire, Durham, N.H. 03824 (email: p_mayewski@unh.edu; gaz@unh.edu).

B. Deck and M. Wahlen, Scripps Institution of Oceanography, University of California, La Jolla, CA 92093-0220 (email: bdeck@ssurf.ucsd.edu; mwahlen@ssurf.ucsd.edu).

P. Chylek, P. Damiano, and B. Johnson, Atmospheric Science Program, Dalhousie University, Halifax, N.S., Canada B3H 3J5 (email: bjohnson@ac.dal.ca).

(Received April 26, 1995; revised March 11, 1996; accepted March 12, 1996.) 